\title{
Urban surface temperature observations from ground-based thermography: intra- and inter-facet variability
}

Article

Accepted Version

Creative Commons: Attribution-Noncommercial-No Derivative Works 4.0

Morrison, W., Kotthaus, S. and Grimmond, S. ORCID: https://orcid.org/0000-0002-3166-9415 (2021) Urban surface temperature observations from ground-based thermography: intra- and inter-facet variability. Urban Climate, 35. 100748. ISSN 2212-0955 doi:

https://doi.org/10.1016/j.uclim.2020.100748 Available at https://centaur.reading.ac.uk/94803/

It is advisable to refer to the publisher's version if you intend to cite from the work. See Guidance on citing.

To link to this article DOI: http://dx.doi.org/10.1016/j.uclim.2020.100748

Publisher: Elsevier

All outputs in CentAUR are protected by Intellectual Property Rights law, including copyright law. Copyright and IPR is retained by the creators or other copyright holders. Terms and conditions for use of this material are defined in the End User Agreement. 


\section{CentAUR}

Central Archive at the University of Reading

Reading's research outputs online 
1 Urban surface temperature observations from ground-based thermography: intra- and inter-facet variability

3 William Morrison ${ }^{\mathrm{a}}$, Simone Kotthaus ${ }^{\mathrm{a}, \mathrm{b}}$, Sue Grimmond ${ }^{\mathrm{a}}$

$4 \quad$ aDepartment of Meteorology, University of Reading, Earley Gate, Reading, RG6 6BB, UK

5 bInstitut Pierre Simon Laplace (IPSL), École Polytechnique, CNRS, Université Paris-Saclay, 91128

6 Palaiseau Cedex, France

7 Abstract

8 Ground based thermal cameras are used to observe urban surface temperatures $\left(T_{\mathrm{s}}\right)$ with an

9 unprecedented combination of: temporal and spatial resolution ( $5 \mathrm{~min}$ and $\sim 0.5 \mathrm{~m} \rightarrow 2.5 \mathrm{~m}$ ), spatial

10 extent (3.9 ha), instrument number (6 static cameras) and surface heterogeneity (mixed high rise and

11 vegetation). Unsupervised classification of images by geometry and material properties (surface orientation, albedo, solar irradiance, and shadow history) is facilitated by a detailed three-dimensional surface model (430 m x $430 \mathrm{~m}$ extent) and sensor view modelling. From detailed source area analysis, $9.5 \%$ of the area is observed by the cameras. Across all camera pixels, the $5^{\text {th }}-95^{\text {th }}$ percentile $T_{\mathrm{s}}$ differences reach $37.5 \mathrm{~K}$ around midday. Roofs have the greatest diurnal $T_{\mathrm{s}}$ range $(290.6 \mathrm{~K} \rightarrow 329.0$ $\mathrm{K}) . T_{\mathrm{S}}$ differences across sunlit sloped roofs reach $23.3 \mathrm{~K}$. Walls of different cardinal orientations consistently differ by $>10 \mathrm{~K}$ between 10:00 and 15:00. Shadow tracking within images is used to model cooling rates, where recently shaded $(<30 \mathrm{~min})$ ground can be $18.6 \mathrm{~K}$ warmer than equivalent unshaded $T_{\mathrm{s}}$. West walls remain warm past sunset and are 1.2 $\mathrm{K}$ warmer than north walls at 23:00 ( 4 hours after sunset). Recently shaded walls cool exponentially to ambient $T_{\mathrm{s}}$ at a similar rate as the ground, but four times slower than roofs. The observed $T_{\mathrm{s}}$ characteristics are anticipated to have a wide range of applications (e.g. evaluation of urban surface energy balance models, ground-truthing of satellite thermal remote sensing).

\section{Introduction}

Urban surface temperature $\left(T_{\mathrm{s}}\right)$ is an important control in the surface energy balance (Krayenhoff and Voogt, 2007) that has distinct characteristics across cities (Offerle et al., 2006). There is increasing interest in $T_{\mathrm{s}}$ observations with high temporal and spatial resolution at facet (e.g. roof, wall, ground) and sub-facet (e.g. materials, shadowing) scales as the degree of urban modelling complexity required for atmospheric models is unclear (Chen et al., 2011). Numerical weather prediction (NWP) frequently characterises the urban surface energy balance by facet (e.g. TEB, Masson, 2000; MORUSES, Porson et al., 2010; SLUCM, Kusaka and Kimura, 2004; BEP, Krayenhoff et al., 2020). Increasingly complex and realistic sub-facet details within urban areas are resolved by models for: computational fluid dynamics (CFD) (Toparlar et al., 2017), sub-facet surface energy balance (e.g. TUF3D, Krayenhoff and Voogt, 2007; THERMORender, Xu and Asawa, 2020), thermal radiation stress (e.g. SOLWEIG, Lindberg and Grimmond, 2011; RayMan, Fröhlich et al., 2019) and building 
energy (e.g. EnergyPlus, Crawley et al., 2001). Such models may have $T_{\mathrm{s}}$ as a prognostic variable which requires observational evaluation across the facets resolved by the model processes.

High temporal and facet-scale resolution urban $T_{\mathrm{s}}$ observation for model evaluation faces many challenges resulting in a general lack of such studies (Toparlar et al., 2017). Exploiting space-borne data for evaluation (e.g. Alexander et al., 2015 using MODIS; Toparlar et al., 2015 using Landsat) is constrained by: low revisit times, a view bias of horizontal surfaces (Hu and Wendel, 2019), and low spatial resolutions such that one pixel may cover the entire model domain (e.g. MODIS, Meteosat Second Generation). Thermal cameras on airborne platforms (e.g. helicopters Hénon et al., 2012; Antoniou et al., 2019; drones Gaitani et al., 2017; Naughton and McDonald, 2019) can view the convoluted urban surface at facet-scale but also have low revisit times and directional view bias (Lagouarde et al., 2004). These studies typically assume no atmospheric effects (Meier et al., 2011; Morrison et al., 2020) on observations. From ground-based platforms, thermal cameras have potential to supersede point-based in-situ sensors (e.g. thermocouples used by e.g. Kanda et al., 2005; Rotach et al., 2005; Pearlmutter et al., 2006) due to higher temporal and spatial resolutions to observe both inter- and intra- facet variations (e.g. Alchapar et al., 2014). A few studies (e.g. low-rise suburb, Adderley et al., 2015; scale model, Morrison et al., 2018) achieve adequate spatial coverage but are limited to simple surface heterogeneity. Ground- or airborne sub-facet thermal imagery across more realistic cities is rare, given the challenges with: logistics to obtain adequate camera views of the convoluted three-dimensional surface and classifying the observations to know what is actually sampled and therefore can/should be compared to model outputs. Sub-facet resolution sampling is done on foot at street level (e.g. Lee et al., 2018) or with vehicle traverses to sample more walls and ground (e.g. Voogt and Oke, 1997; Hilland and Voogt, 2020). Other thermography observations have increased spatial coverage using Asano and Hoyano's (1998) spherical sampling technique (e.g. Acuña Paz y Miño et al., 2020), rotating masts (Adderley et al., 2015), or multiple cameras (e.g. Morrison et al., 2020). Classification methods have used time consuming and subjective techniques such as manual digitisation (Hartz et al., 2006; Lee et al., 2018; Antoniou et al., 2019) or supervised clustering (Voogt and Oke, 1997; Hénon et al., 2012). To expand classification possibilities, Hilland and Voogt (2020) use concurrent visible imagery.

The objectives of this paper are to: (i) outline an unsupervised and objective method to analyse surface-based thermal remote sensing images and (ii) investigate the drivers of urban $T_{\mathrm{s}}$ variability at a high level of detail. The Morrison et al. (2020) London network of six ground-based infrared cameras is used to obtain unprecedented $T_{\mathrm{s}}$ detail ( $5 \mathrm{~min}$ temporal and $\sim 1 \mathrm{~m}$ spatial resolution) for a local-scale area, giving unique insight into urban $T_{\mathrm{s}}$ variability. A digital surface model (DSM) is used with perspective projection and radiative transfer modelling to objectively classify observations by transient sun-surface geometry effects that would not be possible by manual or supervised means. 


\section{Methods}

72 To investigate the drivers of urban $T_{\mathrm{s}}$ variability, ground-based thermal camera observations are

73 processed to determine the surfaces "seen" across a range of scales, from building scale features

74 (facet, orientation and bulk material) through to sun-surface geometry and shadow history at the sub-

75 facet scale.

\subsection{Study area and observations}

77 Observation sites in the Borough of Islington, London, UK $\left(51^{\circ} 31^{\prime} 35^{\prime \prime} \mathrm{N}, 0^{\circ} 06^{\prime} 19^{\prime}\right.$ W) on two high 78 rise residential tower blocks are identified (ID) as "IMU" and "WCT" (IMU at $74 \mathrm{~m}$ agl (above

79 ground level); WCT $36 \mathrm{~m} \mathrm{agl)} \mathrm{(Fig} \mathrm{1a).} \mathrm{The} \mathrm{study} \mathrm{area} \mathrm{covers} \mathrm{a} \mathrm{real} \mathrm{world} \mathrm{(RW)} \mathrm{area} \mathrm{with} \mathrm{irregular}$ 80 street pattern with streets often lined with deciduous trees. There is a mix of residential and 81 commercial buildings (often four to six storeys tall) arranged in terrace rows or large single units (Fig 82 1d). 

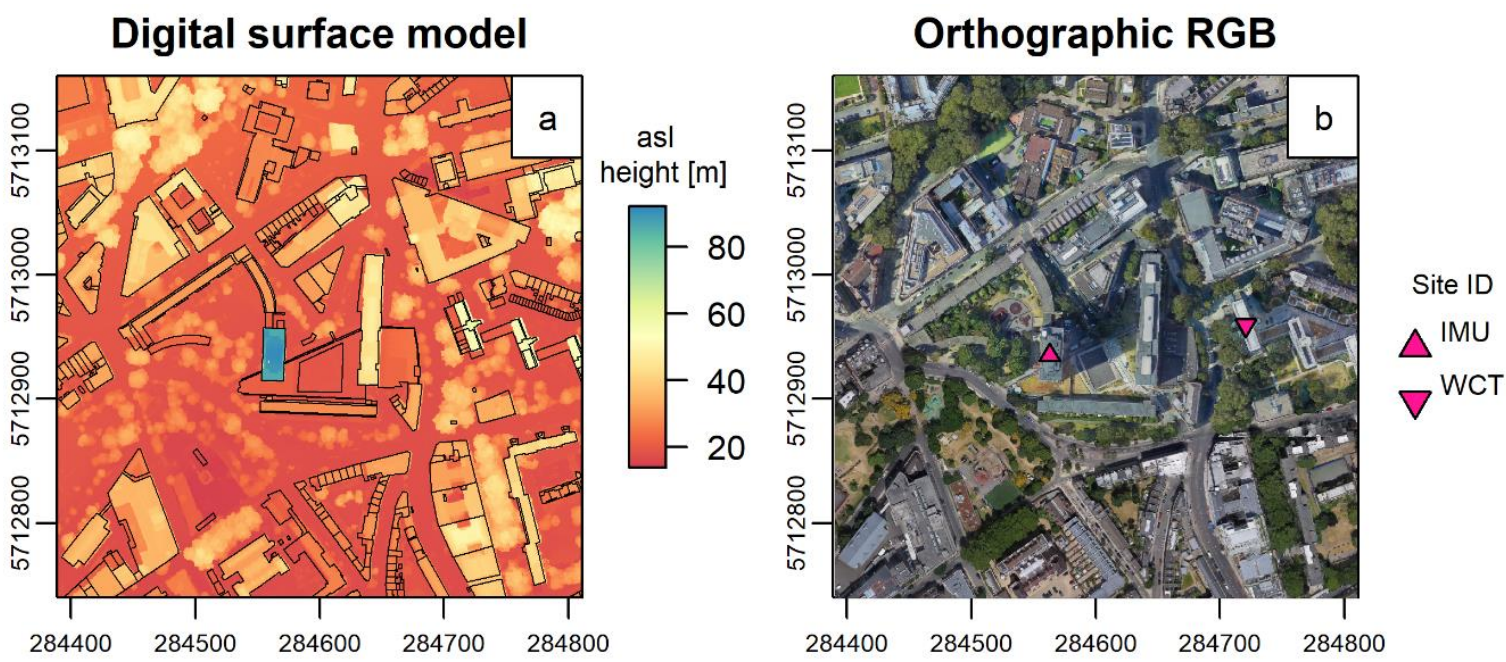

Camera siting
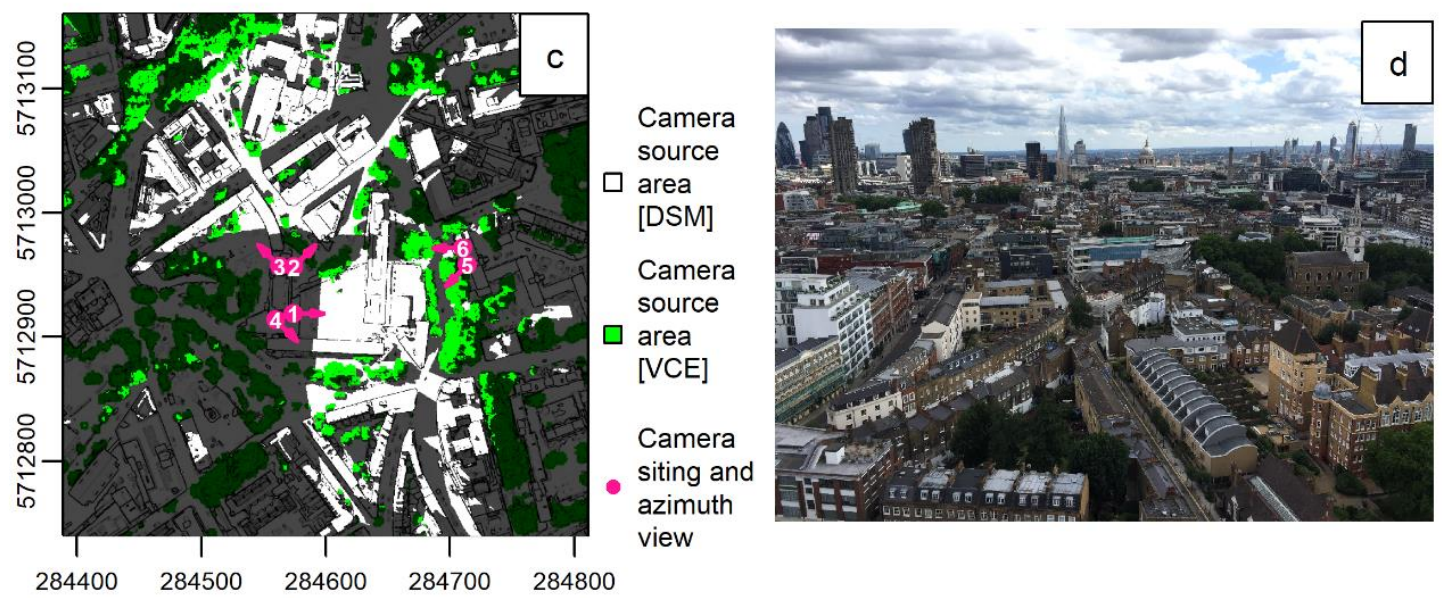

$\begin{array}{lllll}284400 & 284500 \quad 284600 \quad 284700 \quad 284800\end{array}$

Fig 1. Plan view of study area with: (a) height of all surfaces above sea level (asl) with building footprints (black lines, from Evans et al., 2011), (b) orthorectified RGB image from a mosaic of Google Earth (Google, 2019) images with locations (symbols) of the study sites, (c) a render of the "model world" (MW) digital surface model (DSM) and vegetation canopy element (VCE) geometry with DSM (white) and VCE (green) seen by the cameras located (pink dots) around the observation sites with different view directions (pink arrows) and unique camera identification (white) numbers (Table 1 gives details), (d) Digital camera image looking southeast and next to camera number 4 (C4) on 25th Oct 2017. (a - c) use Coordinate Reference System WGS84 UTM grid zone 31N. (a-c) are modified from Morrison et al. (2020).

Optris PI-160 (Optris GmbH, 2018) longwave infrared (LWIR) cameras (Table 1) measure upwelling longwave radiation from the study area (Fig 1c) for $27^{\text {th }}-28^{\text {th }}$ August 2017 (mainly clear-sky summer days). The cameras have multiple view angles (Table 2) allowing various facets of the complete canopy surface to be sampled. Morrison et al. (2020) provide details on the study area and the observations, including: camera siting, measurement procedure, meteorological conditions, and the atmospheric and emissivity corrections of observations to estimate $T_{\mathrm{s}}$ from the at-sensor brightness temperatures. Downwelling shortwave (SW) irradiance $\left(\mathrm{E}_{\mathrm{Sw}^{\downarrow}}, \mathrm{W} \mathrm{m}^{-2}\right)$ from a Davis Vantage Pro 2 weather station located $114 \mathrm{~m}$ agl, $1.1 \mathrm{~km}$ southeast of IMU aids the image classification. 


\begin{tabular}{ll} 
Property & Description \\
\hline Platform & Static ground-based \\
Sample rate & $1 \mathrm{~min}$ \\
Temporal resolution & $5 \mathrm{~min}$ (median of samples at end of interval) \\
Image resolution & $160 \mathrm{x} 120$ pixels \\
Temperature resolution & $0.1 \mathrm{~K}$ \\
Number of cameras & 6 \\
Observation campaign period & 7 th July -10 th Nov 2017 (here $27^{\text {th }}-28^{\text {th }}$ August) \\
Enclosure & Custom built enclosures (Morrison et al., 2020) \\
Radiometric calibration & Manufacturer calibrated 2 months prior to study \\
Accuracy & $\pm 2 \mathrm{~K}$ \\
Spectral range & $7-14 \mu \mathrm{m}$, see Morrison et al. (2020) \\
Image distortion correction & Rectilinear correction; see Morrison et al. (2018) \\
Atmosphere correction & Multi line of sight; see Morrison et al. (2020) \\
Emissivity correction & Corrected for multiple scattering with anisothermal \\
& surface emission; see Morrison et al. (2020)
\end{tabular}

Table 2. Siting properties of the ground based LWIR cameras installed on two high-rise residential towers named "IMU" and

"WCT" within the study area (Fig 1).

\begin{tabular}{cccccc}
$\begin{array}{c}\text { Camera } \\
\text { ID }\end{array}$ & $\begin{array}{c}\text { Location } \\
\text { Site ID }\end{array}$ & $\begin{array}{c}\text { Field of View }\left(^{\circ}\right) \\
\text { horizontal x vertical }\end{array}$ & $\begin{array}{c}\text { Cardinal } \\
\text { Facing }\end{array}$ & $\begin{array}{c}\text { Viewing } \\
\text { Zenith Angle }\left(\Theta,{ }^{\circ}\right)\end{array}$ & $\begin{array}{c}\text { Median Path } \\
\text { Length }(\mathrm{m})\end{array}$ \\
\hline C1 & IMU & $68.6 \times 54.2$ & $\mathrm{E}$ & 46.5 & 88.8 \\
C2 & IMU & $62.6 \times 49.1$ & NE & 51.7 & 97.9 \\
C3 & IMU & $62.8 \times 49.2$ & NWW & 52.9 & 106.6 \\
C4 & IMU & $37.3 \times 28.4$ & SE & 56.7 & 122.7 \\
C5 & WCT & $38.4 \times 29.3$ & SW & 66.6 & 79.0 \\
C6 & WCT & $62.4 \times 48.9$ & W & 61.7 & 67.5
\end{tabular}

\subsection{Image classification}

To facilitate image classification, the RW study area and instrumentation are represented in a "model world" (MW). The MW uses a vector-based 3D DSM with a 3D mesh of triangles and a voxelated representation of vegetation covering the RW study area (Fig 1). The DSM extends $430 \mathrm{~m}$ x $430 \mathrm{~m}$ horizontally to cover the camera source areas. The MW also uses sensor view modelling to replicate the RW camera perspectives (hereafter "MW cameras"), whereby the DSM is projected on to the MW camera image plane, using a pinhole camera projection (Hartley and Zisserman, 2004).

110 Modelled camera perspectives determine various surface types "seen" by each camera pixel (x, y).

111 Types of surface are differentiated by class $(i)$ at timestep $\mathrm{t}$ for each pixel $[i(\mathrm{x}, \mathrm{y}, \mathrm{t})]$. Within class $i$,

112 three surface properties are defined (Table 3): orientation and material $(\Sigma)$, sun-surface geometry

113 (bidirectional reflectance factor, BRF) and shadow history (time in shade, $\mathrm{t}_{\text {shd, }}$ min). Thus $i$ principally

114 describes sun-surface geometry which is a key driver of $T_{\mathrm{s}}$ variability (Krayenhoff and Voogt, 2016;

115 Morrison et al., 2018).

116 Many features of the MW are created and managed by the Discrete Anisotropic Radiative Transfer 117 (DART) model (Gastellu-Etchegorry et al., 2012). DART allows 3D radiative transfer (RT) processes 118 to be simulated in both natural and urban landscapes in the visible to LWIR regions of the 
electromagnetic spectrum using a ray tracing approach. Here DART is used to simulate the BRF "seen" by each MW camera pixel, shown by Morrison et al. (2018) for simple building geometry to differentiate sunlit and shaded areas. For a full description of DART see Gastellu-Etchegorry et al. (2015).

Orientation and material (Table 3 ) for each camera pixel $[\Sigma(\mathrm{x}, \mathrm{y})$, Fig $2 \mathrm{~b}]$ is obtained using Blender rendering software (Blender, 2018), where DSM triangle colours are rendered for each MW camera image perspective (Morrison et al., 2018 for details). A pixel is $\Sigma_{\text {mixed }}(\mathrm{x}, \mathrm{y})$ (dark grey, Fig 2b) if it (a) has more than one surface and orientation property rendered or (b) views surfaces beyond the MW extent (e.g. Fig $2 \mathrm{~b} \mathrm{C} 2$, top of image). Pixels manually masked $\left[\Sigma_{\text {masked }}(\mathrm{x}, \mathrm{y})\right]$ from further analysis include near-field IMU and WCT roofs which are challenging to align, a low emissivity metal roof (C2, Fig 2b) and the corner of the $\mathrm{C} 1$ enclosure (Fig 2b, top left). Compared to prior studies that manually classify images, our classification is objective and automated but typically has fewer classes. Christen et al.'s (2012) images classified by manual inspection and digitisation (see their Fig 1d) include e.g. brick/painted walls and tile/gravel roofs by manual inspection and digitisation. Inclusion of such classes here - in $\Sigma$ and across Fig $2 \mathrm{~b}$ - would require a similarly classified DSM which was not available in this study.

To determine the sun-surface geometry characteristics (Table 3), all MW surfaces, including vegetation canopy elements, are defined in DART as opaque Lambertian reflectors. Direct downwelling spectral irradiance $\left(\mathrm{E}_{\lambda} \downarrow\right.$,dir, $\left.\mathrm{W} \mathrm{m}^{-2} \mu \mathrm{m}^{-1}\right)$ is simulated by DART at $0.5 \mu \mathrm{m}$ wavelength $(\lambda$, bandwidth $\Delta \lambda=0.01 \mu \mathrm{m}$ ). Rays originate from a horizontal layer just above the tallest building ( 625 rays $\left.\mathrm{m}^{-2}\right)$ and are tracked downward with spectral radiant flux density $\mathrm{E}_{\lambda}(\theta, \phi, \Omega, \mathrm{t})\left(\mathrm{W} \mathrm{m}^{-2} \mu \mathrm{m}^{-1}\right)$ along solid angle $\Omega$ (sr) and direction $(\theta, \phi)$ at timestep t. $\mathrm{E}_{\lambda}(\theta, \phi, \Omega, \mathrm{t})$ intercepted by the MW surface is scattered for all possible scattering directions, according to the surface position and orientation. Scattered rays that intercept the image plane of a MW camera are used by DART to calculate atsensor spectral radiance $\left[\mathrm{L}_{\lambda}^{\mathrm{cam}}(\mathrm{x}, \mathrm{y}, \mathrm{t}), \mathrm{W} \mathrm{m}^{-2} \mathrm{sr}^{-1} \mu \mathrm{m}^{-1}\right]$.

The BRF across the camera images is calculated as:

$$
\operatorname{BRF}(x, y, t)=\frac{\pi L_{\lambda}^{\text {cam }}(x, y, t, \Omega)}{E_{\lambda}^{\downarrow, d i r}(t)} .
$$

For a shaded surface BRF is zero. $B R F=1$ for sunlit horizontal surfaces (i.e. surfaces plane-parallel to the ground) regardless of daytime sun angle and camera view angle, as $E_{\lambda} \downarrow$,dir is referenced to a horizontal layer. The BRF of a non-flat surface departs from unity. BRF increases as the sun angle becomes perpendicular to the surface, and vice versa. For example, in the northern hemisphere, east facing walls have the highest BRF in the early morning, decreasing through the morning as the sunsurface angle becomes more oblique. 
151 A low density of rays incident on a surface can occur if the direct-beam solar radiation is near-

152 perpendicular to a surface and/or when the sun angle is low relative to the surface. This can cause 153 inaccuracies and erroneous patterns in $\operatorname{BRF}(x, y)$ and isolated "sunlit" pixels $[B R F(x, y)>0]$ (i.e. 154 none of the surrounding 8 pixels have $\operatorname{BRF}(x, y)>0)$. To resolve this, in this study we reassign these 155 pixels to $\Sigma_{\text {mixed }}(\mathrm{x}, \mathrm{y})$. Where $\mathrm{BRF}(\mathrm{x}, \mathrm{y}, \mathrm{t})$ has a continuous scale, the final surface property for analysis 156 is $\overline{\operatorname{BRF}}(\mathrm{x}, \mathrm{y}, \mathrm{t})$, which is $\operatorname{BRF}(\mathrm{x}, \mathrm{y}, \mathrm{t})$ binned (indicated by overbar) between $0 \rightarrow 2$ using a bin width 157 of 0.25 . The bins are centre labelled. The first bin is 0 and is for values between 0 and 0.125 e.g. $158 \operatorname{BRF}(x, y, t)=0.10$ is assigned to $\overline{\operatorname{BRF}}(x, y, t)=0$; the second bin is 0.25 and has values between 1590.125 and 0.375 e.g. $\operatorname{BRF}(x, y, t)=0.13$ is assigned $\overline{\operatorname{BRF}}(x, y, t)=0.25$; etc. To differentiate shaded 160 pixels $[\mathrm{BRF}(\mathrm{x}, \mathrm{y}, \mathrm{t})=0]$ from the lowest $\overline{\mathrm{BRF}}$ bin $(\overline{\mathrm{BRF}}(\mathrm{x}, \mathrm{y}, \mathrm{t})=0)$, pixels with $\mathrm{BRF}(\mathrm{x}, \mathrm{y}, \mathrm{t})<0.05$ on timesteps with no direct solar radiation are assigned to a separate bin, $\overline{B R F}(x, y, t)=-1$ for analysis. $E_{S w} \downarrow$ observations (Section 2.1) are considered to have no direct solar radiation if they fall below a threshold of modelled clear-sky direct and diffuse insolation (Bird and Hulstrom, 1981, model implemented in solaR software, Perpiñán, 2012).

165 Shadow history is defined for the time a surface has spent in shade $\left(\mathrm{t}_{\text {shd }}, \min \right)$ (Table 3$)$ and is 166 determined by comparison of $\overline{\operatorname{BRF}}(x, y, t)$ to the prior timestep $[\overline{\mathrm{BRF}}(\mathrm{x}, \mathrm{y}, \mathrm{t}-5 \mathrm{~min})]$. If a surface 167 becomes shaded at time $t$, it has spent $t_{s h d}(x, y, t)=5 \mathrm{~min}$ in shade. For the timestep prior to this $(t-5$ $168 \mathrm{~min})$, the surface has spent zero minutes in shade and has $\mathrm{t}_{\text {shd }}(\mathrm{x}, \mathrm{y}, \mathrm{t}-5 \mathrm{~min})=0 \mathrm{~min}$. A surface that 169 continues to be in shade [i.e. $\overline{\mathrm{BRF}}(\mathrm{x}, \mathrm{y}, \mathrm{t}+5 \min )=-1$ ] has $\mathrm{t}_{\text {shd }}(\mathrm{x}, \mathrm{y}, \mathrm{t}+5 \mathrm{~min})=10 \mathrm{~min}$ at the next 170 timestep, etc. As a pixel can view a surface that is part sunlit and part shaded across multiple timesteps, these pixels are designated fully sunlit or fully shaded based on the 10-timestep (50 min) window around each timestep. If a pixel has $\overline{\mathrm{BRF}}(\mathrm{x}, \mathrm{y}, \mathrm{t})>-1$, is sunlit at $\mathrm{t}-25$ min and shaded at $\mathrm{t}+$ $25 \mathrm{~min}$, then it is considered partially sunlit at $\mathrm{t}$. In these cases, the following threshold is used to determine if the observed surface is more shaded than sunlit and $t_{\text {shd }}(x, y, t)$ is updated accordingly:

$$
\mathrm{t}_{\text {shd }}(\mathrm{x}, \mathrm{y}, \mathrm{t})=\left\{\begin{array}{ll}
0 & \text { if } \operatorname{BRF}(\mathrm{x}, \mathrm{y}, \mathrm{t})<[0.75 \cdot \operatorname{BRF}(\mathrm{x}, \mathrm{y}, \mathrm{t}-25 \mathrm{~min})] . \\
5 & \text { otherwise }
\end{array} .\right.
$$

If $t_{\text {shd }}(x, y, t)=0$, pixels are allocated the maximum $\overline{B R F}(x, y)$ that occurred up to 5 timesteps prior 176 (i.e. $\max \{\overline{\mathrm{BRF}}(\mathrm{x}, \mathrm{y}, \mathrm{t}-25 \mathrm{~min} \rightarrow 0)\})$ to assign partially shaded pixels with a fully sunlit status. 

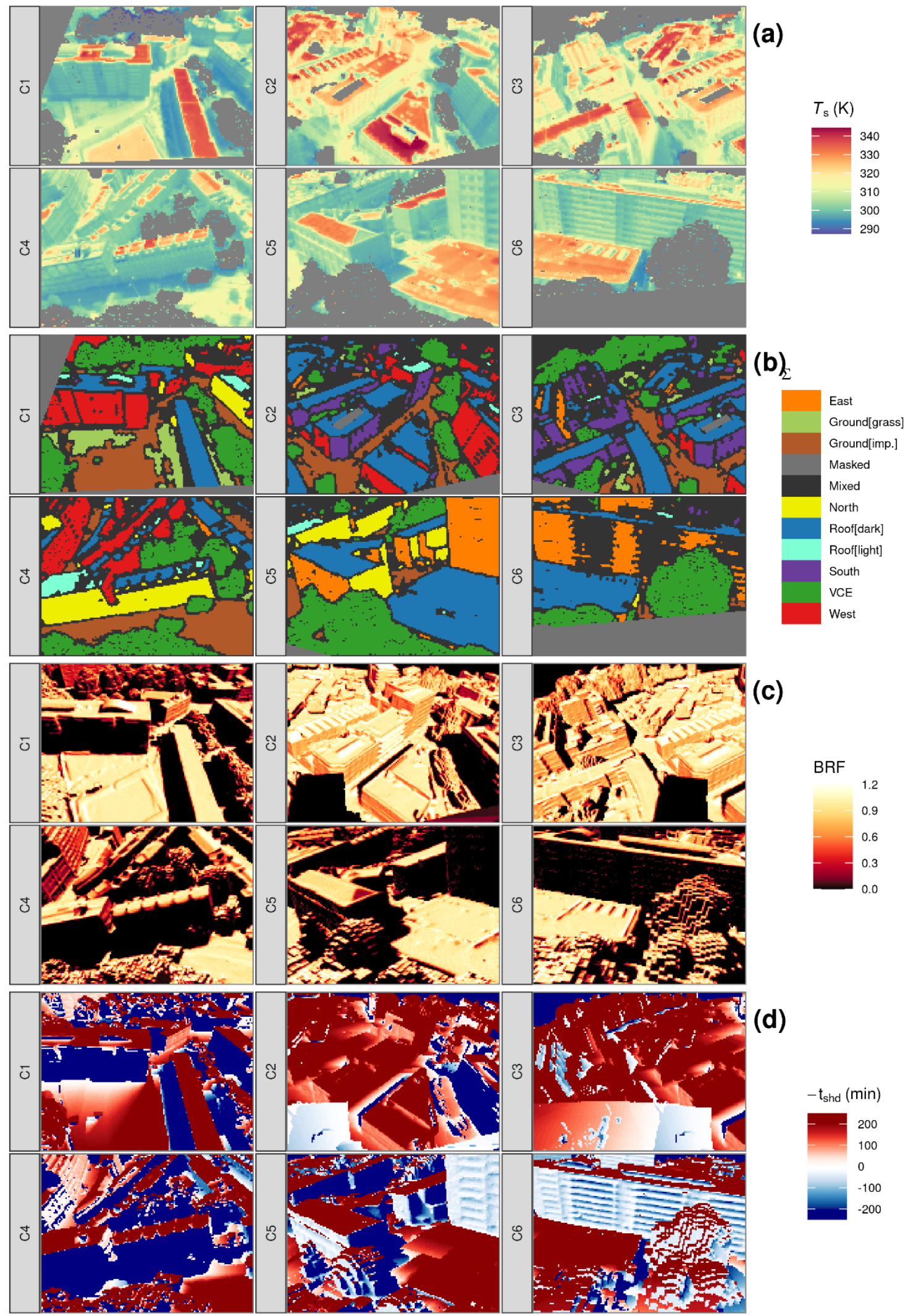

Fig 2. (a) Optris PI longwave infrared (LWIR) camera observations for $27^{\text {th }}$ August 2017 12:00 UTC and (b - d) simulated surface properties projected onto the image plane of "model world" (MW) cameras that simulate the perspective of (a). Surface properties are: (b) orientation and material $(\Sigma)$, (c) shortwave bidirectional reflectance factor (BRF) to determine sun-surface geometry assuming Lambertian reflecting surfaces, and (d) time surfaces have spent in shade ( $t_{\text {shd, }}$, white $\rightarrow$ blue) or sun (white $\rightarrow$ red). The cameras (Table 2 ) are indicated to the left of each image. (a-b) are modified from Morrison et al. (2020). 
Table 3. Surface properties of orientation and material $(\Sigma)$, bidirectional reflectance factor (BRF) and shadow history ( tshd $_{\text {sh }}$ used for per-pixel classification of LWIR camera observations (Fig 2). A surface class ( $i$ ) has three surface properties: $\Sigma, \overline{B R F}$, tshd.

\begin{tabular}{|c|c|c|c|c|c|c|}
\hline & Property & Method & Description & Values & & Example \\
\hline$\Sigma$ & $\begin{array}{l}\text { Orientation and } \\
\text { material }\end{array}$ & $\begin{array}{l}\text { Blender 3D modelling } \\
\text { Land cover map } \\
\text { Airborne hyperspectral } \\
\text { (Morrison } \text { et al., 2020) }\end{array}$ & $\begin{array}{l}\text { Cardinal } \\
\text { orientation } \\
\text { and material }\end{array}$ & $\begin{array}{l}\text { Roof[dark] } \\
\text { Roof[light] } \\
\text { Ground[imp.] } \\
\text { Ground[grass] } \\
\text { North } \\
\text { East }\end{array}$ & $\begin{array}{l}\text { South } \\
\text { West } \\
\text { Down } \\
\text { Mixed } \\
\text { Masked }\end{array}$ & $\begin{array}{l}\text { Fig } 2 b \\
\text { Fig } 3\end{array}$ \\
\hline$\overline{\mathrm{BRF}}$ & $\begin{array}{l}\text { Sun-surface } \\
\text { geometry }\end{array}$ & DART simulation & $\begin{array}{l}\text { DART } \\
\text { bidirectional } \\
\text { reflectance } \\
\text { factor (BRF) } \\
\text { simulation }\end{array}$ & \multicolumn{2}{|c|}{$\begin{array}{l}\text { BRF binned }(\overline{\mathrm{BRF}}) \text { as } 0 \rightarrow 2 \\
\text { at } \Delta 0.25 \text { (unitless). Shaded } \\
\text { surfaces }(\mathrm{BRF}<0.05) \text { are } \\
\text { assigned to bin } \overline{\mathrm{BRF}}=-1\end{array}$} & Fig 2c \\
\hline$t_{\text {shd }}$ & Shadow history & DART simulation & Time in shade & \multicolumn{2}{|c|}{$0 \rightarrow 2 \tau \Delta 5(\mathrm{~min})$} & Fig $2 d$ \\
\hline
\end{tabular}




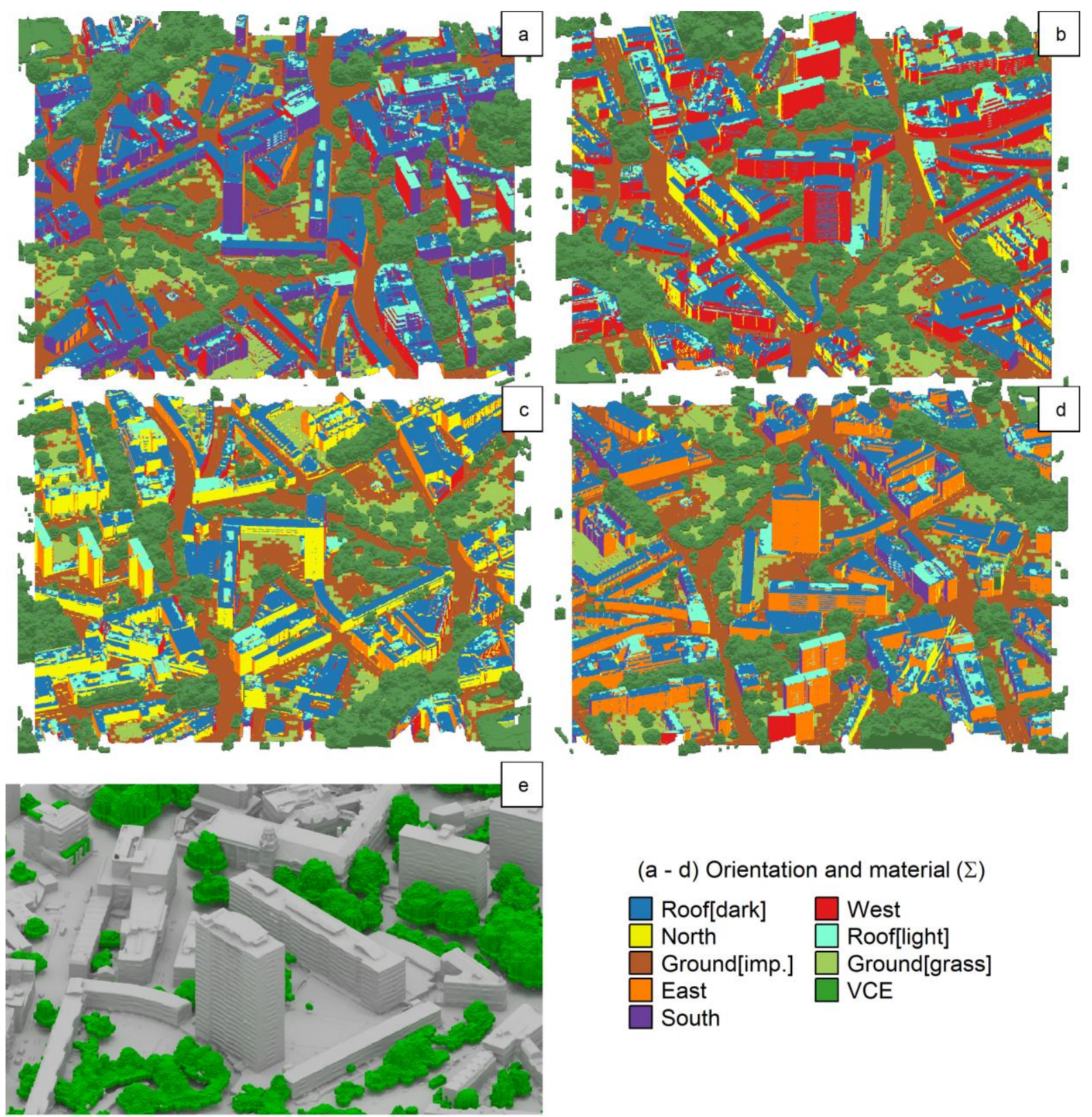

Fig 3. Vector digital surface model (DSM) and vegetation canopy elements (VCE) for the study area created from Google Earth (Google, 2019; Morrison et al., 2020) imagery with (colours) orientation and material surface properties $(\Sigma)$ rendered in Blender (Blender, 2018) for off-nadir view directions facing: (a) north, (b) east, (c) south, (d) west and (e) northeast with focus on the study sites and surface geometry, rendered without $\Sigma$. VCE covers a slightly larger area than the DSM.

\subsection{Cooling events}

A "cooling event" time window is used to analyse the shadow history (Section 2.2) effect on observed $T_{\mathrm{s}}$. This starts when a pixel is sunlit for the last time $\left(\mathrm{t}_{\mathrm{shd}}(\mathrm{x}, \mathrm{y})=0 \mathrm{~min}\right)$ and ends when it is substantially cooled $\left(\mathrm{t}_{\mathrm{shd}}(\mathrm{x}, \mathrm{y})>\mathrm{n} \tau\right)$, with time constant $\tau(\mathrm{min})$ and multiplicative factor $\mathrm{n}$. A cooling event can continue after sunset and across days. To determine a representative time window for cooling events, $\tau$ is calculated using an exponential rate of cooling (Vollmer, 2009) for all pixels that enter shade as:

$$
\mathrm{T}_{\mathrm{S}}[\mathrm{a}]=\mathrm{T}_{\mathrm{s}}[\mathrm{b}]+\left(\mathrm{T}_{\mathrm{s}}[\mathrm{c}]-\mathrm{T}_{\mathrm{s}}[\mathrm{d}]\right) \mathrm{e}^{\left(-\frac{\mathrm{t}}{\tau}\right)}
$$


using $T_{\mathrm{s}}$ observation subsets (Table 4$)$. In Eqn. 3 , the $T_{\mathrm{s}}$ difference for recently shaded ( $\left.T_{\mathrm{s}}[\mathrm{a}]\right)$ and prolonged shaded $\left(T_{\mathrm{S}}[\mathrm{b}]\right.$, hereafter "ambient" $\left.T_{\mathrm{s}}\right)$ surfaces throughout the cooling event isolates the rate of cooling from any ambient variations in surface temperature. The ambient temperature is included in the cooling event definition as it isolates the direct solar irradiance component of the surface energy balance from all other energy balance processes. These include variations in sensible heat exchange (from e.g. wind speed and direction), incoming diffuse radiation (due to e.g. patchy cloud or day-night transition) and heat storage. After $\tau$ minutes, the temperature difference is reduced to $1 / \mathrm{e}(\sim 0.368)$ of the value at $t_{\text {shd }}=0$ (Vollmer and Möllmann, 2017).

Table 4. Surface temperature sub-classes used to determine exponential cooling (Eqn. 3). See text and Table 3 for definitions. Cooling event lengths $(\mathrm{n} \tau)$ have units of minutes

\begin{tabular}{|l|l|l|}
\hline & Surface temperature $\left(\boldsymbol{T}_{\mathrm{s}}\right)$ description & Definition \\
\hline$T_{\mathrm{s}}[\mathrm{a}]$ & Pixel $T_{\mathrm{s}}$ with time in shade no longer than $\mathrm{n} \tau$ & $T_{\mathrm{s}}\left(\mathrm{x}, \mathrm{y}, \Sigma, \overline{\mathrm{BRF}}>-1, \mathrm{t}_{\text {shd }}>0 \& \leq \mathrm{n} \tau, \mathrm{t}\right)$ \\
\hline$T_{\mathrm{s}}[\mathrm{b}]$ & $\begin{array}{l}\text { Ambient } T_{\mathrm{s}} \text { at time } \mathrm{t} \text {, aggregated (median) from pixels in } \\
\text { shade for more than } \mathrm{n} \tau\end{array}$ & $T_{\mathrm{s}}\left(\Sigma, \overline{\mathrm{BRF}}=-1, \mathrm{t}_{\text {shd }}>\mathrm{n} \tau, \mathrm{t}\right)$ \\
\hline$T_{\mathrm{s}}[\mathrm{c}]$ & $\begin{array}{l}\text { Pixel } T_{\mathrm{s}} \text { at the timestep prior to shadowing }\left(\mathrm{t}_{\text {shd }}=0\right), \text { i.e. at } \\
\text { start of the cooling event }(\mathrm{t}=0)\end{array}$ & $T_{\mathrm{s}}\left(\mathrm{x}, \mathrm{y}, \Sigma, \overline{\mathrm{BRF}}>-1, \mathrm{t}_{\text {shd }}=0, \mathrm{t}=0\right)$ \\
\hline$T_{\mathrm{s}}[\mathrm{d}]$ & $\begin{array}{l}\text { Ambient } T_{\mathrm{s}} \text { at the timestep prior to shadowing }(\mathrm{t}=0), \\
\text { aggregated (median) from pixels in shade for more than } \mathrm{n} \tau\end{array}$ & $T_{\mathrm{s}}\left(\Sigma, \overline{\mathrm{BRF}}=-1, \mathrm{t}_{\text {shd }}>\mathrm{n} \tau, \mathrm{t}=0\right)$ \\
\hline
\end{tabular}

211 Cooling event lengths $(\mathrm{n} \tau)$ need to be initially estimated. Using all pixels within a day for a given 212 surface orientation and material, $\mathrm{n} \tau$ is set at $15 \mathrm{~min}$ and increased incrementally until the majority of 213 observations are at ambient $T_{\mathrm{s}}$; i.e. when $>68 \%$ of pixels with $\mathrm{t}_{\mathrm{shd}}(\mathrm{x}, \mathrm{y})=\mathrm{n} \tau$ have an exponentially 214 cooled $T_{\mathrm{s}}\left(T_{\mathrm{s}}[\mathrm{a}]\right)$ that is lower than the ambient temperature $\left(T_{\mathrm{s}}[\mathrm{b}]\right.$, median) plus one standard 215 deviation. Cooling events are only considered if a pixel has a temperature recorded at $t_{\text {shd }}(x, y)=0$ and $216 \mathrm{t}_{\mathrm{shd}}(\mathrm{x}, \mathrm{y})=\mathrm{n} \tau$.

217 To demonstrate cooling events, $T_{\mathrm{s}}(\mathrm{x}, \mathrm{y})$ for recently shaded surfaces (Fig 4a, black and grey) and an 218 aggregated value of all pixels viewing surfaces that have been shaded for an extended $(>n \tau)$ period 219 ("ambient" temperature, Fig 4a, blue) are compared over $1.5 \mathrm{~h}$ (Fig $4 \mathrm{~b}$ is one randomly selected cooling event). From this, $\tau(\mathrm{x}, \mathrm{y}, \mathrm{t})$ (Eqn. 3) is estimated using a nonlinear least squares (NLS) model fit for all per-pixel cooling events (Fig 4b, red). Across all pixels during the study date, the NLS fit of $\tau(\mathrm{x}, \mathrm{y}, \mathrm{t})$ is rejected if (1) it contains less than 5 timesteps, (2) the pixel surface property becomes "mixed" (Section 2.2) at any point during the event, (3) the NLS fit fails to converge, or (4) $\tau(x, y, t)>$ $1000 \mathrm{~min}$. A generalised modelled value of $\tau$ uses the median value of $\tau(\mathrm{x}, \mathrm{y}, \mathrm{t}, \Sigma)$ determined from all eligible cooling events across the study date as one representative time constant for three surface types: roofs, walls, and ground $[\tau(\Sigma)]$. 


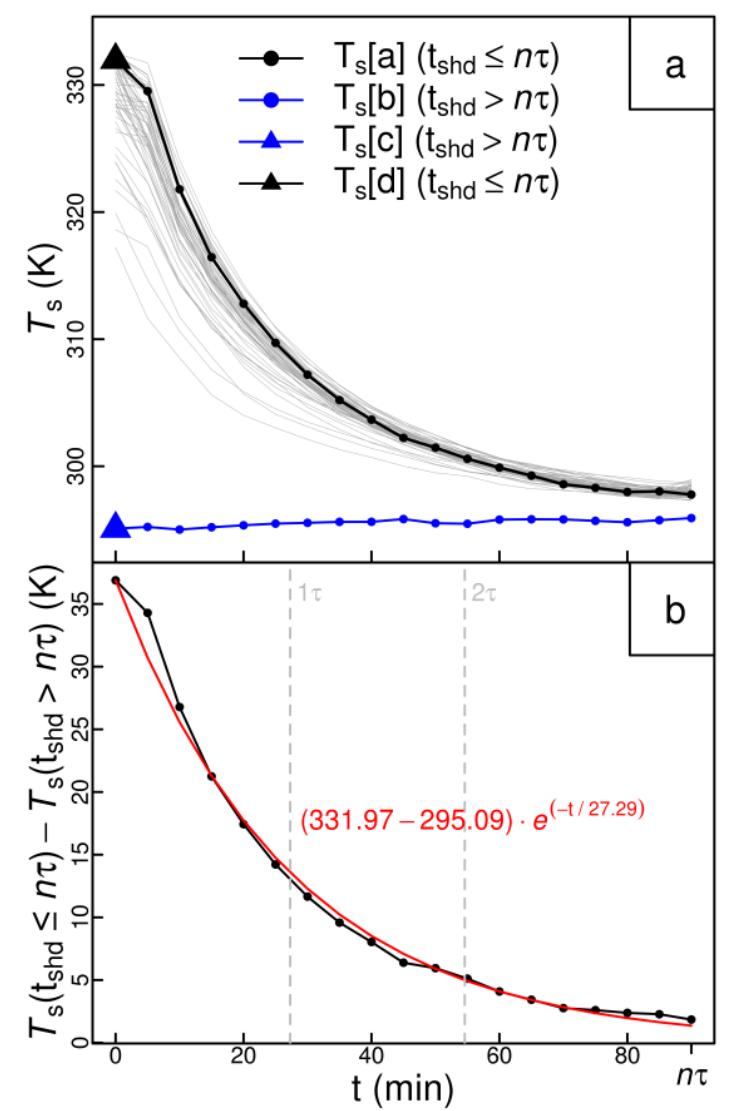

\section{Observational source area}

234 Of the total model world (MW) surface area $\left(\mathrm{A}_{\text {тотАL }}=4.1 \times 10^{5} \mathrm{~m}^{2}\right.$, Fig 5), $88.0 \%$ is composed of

235 DSM triangles and the remainder $(12.0 \%)$ is from the vegetation canopy elements (VCE) plan area.

236 East and west walls are $23.3 \%$ of Атотан compared to $18.3 \%$ for north and south walls. These

237 numbers are not equal as the MW buildings are not cuboids and some are cut off at the MW edges

238 (Fig 3). The ground surfaces (30.3\%) (e.g. streets, parks, courtyards) have greater area than the roofs

239 (15.6\%). Roofs mostly have low albedo (Roof[dark], $12.8 \%$ ).

240 The overall camera source area $\left(\mathrm{A}_{\mathrm{CAM}}\right)$ is $38,950 \mathrm{~m}^{2}\left(9.5 \%\right.$ of $\left.\mathrm{A}_{\text {TOTAL }}\right)$, approximated as the summed 241 area of triangles completely within the field of view of any camera. ACAm excludes VCE directly but 242 resolves the occlusion of other surfaces by VCE. Where cameras have overlapping source areas (Fig 243 1c, Fig 2) the overlapping area is allocated arbitrarily to the camera with lowest ID (Table 2). With 244 A $_{\text {CAM }}$ calculated using the DSM triangles (not rendered images), it includes all mixed ("complex" 245 geometry) and masked (near field objects, e.g. roofs directly beneath cameras, Fig 2b) pixels causing 246 a small overestimation of $\mathrm{A}_{\mathrm{CAM}}$. $\mathrm{A}_{\mathrm{CAM}}$ may further underestimate the actual source area of classified 247 pixels, as partially visible triangles (MW camera field of view) are rejected. 


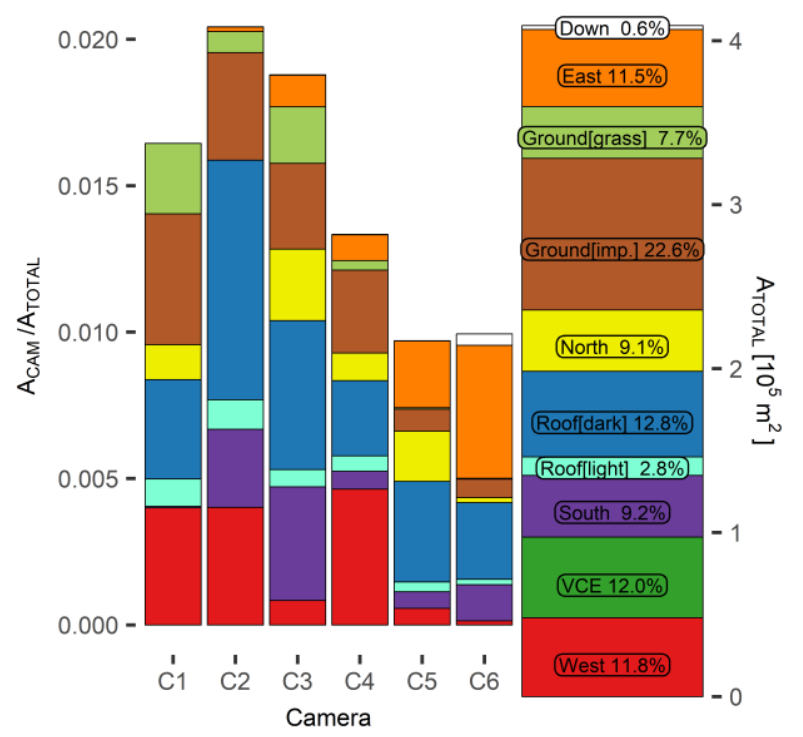

Fig 5. Total three-dimensional study surface area (AтотAL) and area seen by the LWIR cameras (AcAm) (Table 2) classified by surface and orientation properties (colours).

Inter-camera differences in $\mathrm{A}_{\mathrm{CAM}}$ result from camera siting height, zenith view angle and the occlusion of far-field surfaces by near-field objects. Located at $75 \mathrm{~m}$ agl with an oblique view angle, camera $\mathrm{C} 2$ has the largest source area (2\% of MW area, Fig 5) whereas C5 and C6, mounted at $37 \mathrm{~m}$ agl, have the smallest source areas ( $\sim 1 \%$ of MW each). Roof and ground surfaces are observed by all cameras. The oblique view angles mean vertical facets substantially contribute to the observational source area, but the actual vertical facets sampled depends on the camera azimuth. A camera can view surfaces with opposing directions (e.g. east and west) due to the grouping of the heterogeneous wall facings into the four cardinal directions.

For pixel-level source areas, the manual approach used to determine $\mathrm{A}_{\mathrm{CAM}}$ (Fig 5) is too time consuming to conduct for each of the $1.15 \times 10^{5}$ individual pixels. Variations in surface area coverage across each camera IFOV (instantaneous field of view) are not accounted for and pixels are assumed to have equal source areas. The azimuth and zenith of DSM triangles within each camera pixel IFOV are given in Fig 6. The distribution of surface azimuth angles for the walls is uneven (Fig 6a). Some angles have many samples (maximum $=2677$ pixels, for $342.5^{\circ} \rightarrow 347.5^{\circ}$ ) and others far fewer $\left(\right.$ minimum $=130$ pixels, for $\left.127.5^{\circ} \rightarrow 132.5^{\circ}\right)$ as building walls have a few fixed directions and sensors have limited views (Table 2). Given the complexity of the study area geometry, the azimuthal facings are well distributed within each wall orientation bin (Fig 6a, between vertical dashed lines) except for the $\Sigma_{\text {South }}$ where a view bias of southeast facing $\left(\theta \approx 135^{\circ} \rightarrow 150^{\circ}\right.$, Fig 6a) surfaces is found. This is explained by the southwest-to-northeast street orientation sampled by the northward facing cameras (C2 and $\mathrm{C} 3)$.

Sloped roofs, chimneys, balconies and other micro-scale geometry resolved in the DSM widen the surface zenith angle distribution (Fig 6b). The incorrect classification of highly sloped roofs as walls and the DSM "rounding" of corners over short $(<1 \mathrm{~m})$ distances also contribute towards this broad 
surface zenith angle distribution. Most observed walls are vertical (median $90.83^{\circ}$ ) with variability $\left( \pm 11.07^{\circ}\right.$ standard deviation) from the sub-facet wall geometry (e.g. balconies). Roof pixels are mainly flat (median $176.74^{\circ}$ ). Here, slight slopes (e.g. 8579 pixels sample roofs with surface zenith angle between $177.50^{\circ}$ and $178.25^{\circ}$ ) may result from inaccuracies in the DSM, as these pixels most likely view flat roofs in the RW.
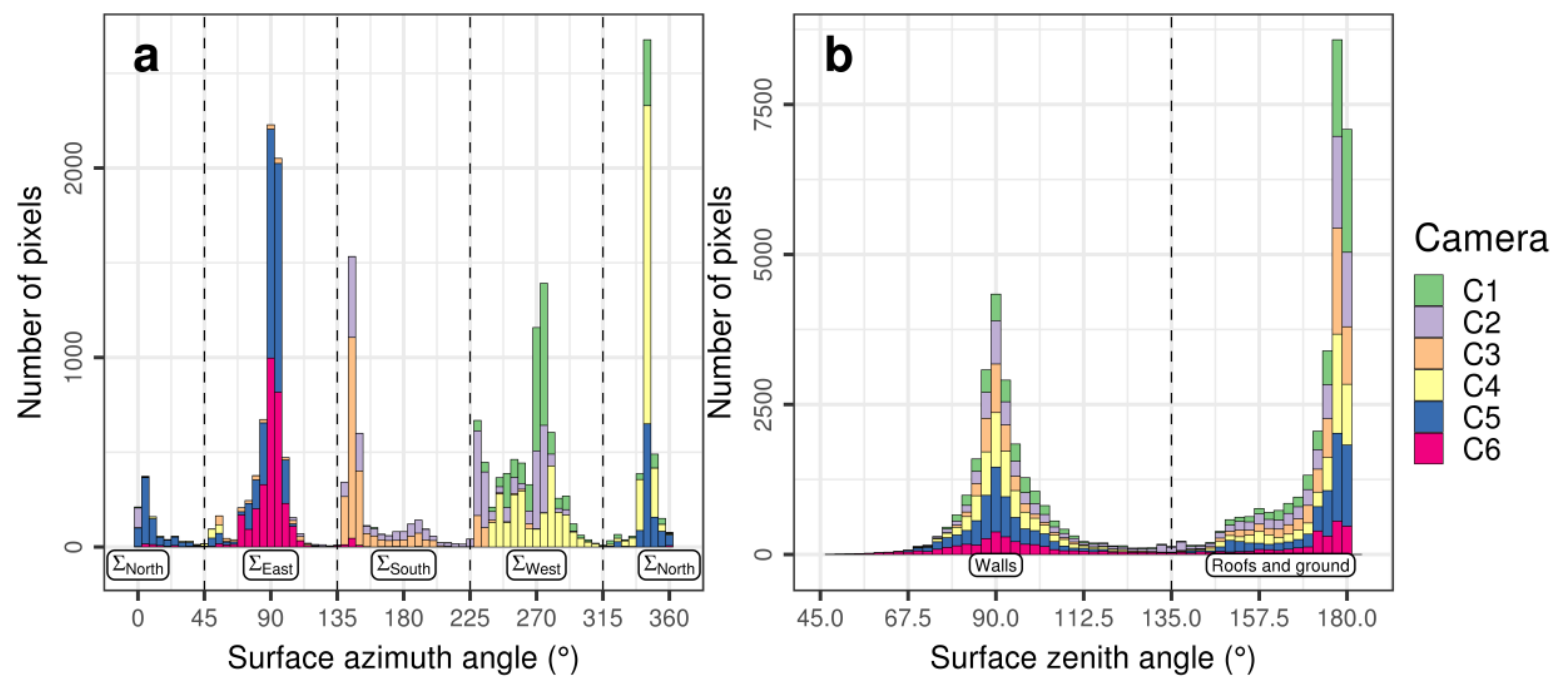

Fig 6. Frequency of pixels by surface orientations within the instantaneous field of view (IFOV) of each camera (excluding vegetation canopy elements (VCE) but including "mixed" and "masked" pixels) for (a) azimuth facing (zenith angle $<135^{\circ}$ ), and (b) zenith angles of pixels. Azimuth angle of $0^{\circ}\left(180^{\circ}\right)$ is north (south) for WGS84 UTM grid zone $31 \mathrm{~N}$. Pixels with a zenith angle of $90^{\circ}\left(180^{\circ}\right)$ face vertically (horizontally).

\section{Surface temperature variability by class}

To quantify the role of surface class on $T_{\mathrm{s}}$ variability, the permutations of surface class in the observations (Table 3) are considered by scale:

287 1) building scale variability (facet, orientation, and material $\Sigma$, e.g. Fig $2 b$ ),

288 2) sub-facet variability within a surface orientation (e.g. different roof slopes) related to the sunsurface geometry ( $\overline{\mathrm{BRF}}$, e.g. Fig $2 \mathrm{c})$, and

290 3) shadow history with high spatial resolution ( $t_{\text {shd, }}$ e.g. Fig $\left.2 d\right)$.

\subsection{Variability from surface orientation and material at the building scale}

292 Across all pre-classified observations (Fig 7a, white) the overall $T_{\mathrm{s}}$ difference is $37.5 \mathrm{~K}$ between the $293 \quad 5^{\text {th }}$ percentile $\left(\mathrm{P}_{5}\right)$ and $\mathrm{P}_{95}$ during the period 12:00 - 12:55 (hereafter referred to by time ending, i.e.

294 13:00). Mixed pixels (Fig 7a, grey), primarily walls with complex small-scale features (e.g. balconies

295 - C6, Fig 2a, b), are generally cooler than roof and ground surfaces, with a smaller hourly and diurnal 296 range than the pre-classified temperatures. Hilland and Voogt (2020) resolve these small-scale 297 features and find self-shading significantly reduces facet averaged $T_{\mathrm{s}}$ by around $1-6 \mathrm{~K}$.

298 With our coarsest surface classification (i.e. building facets, orientations and materials) roof $T_{\mathrm{s}}$, as expected (Voogt and Grimmond, 2000; Christen et al., 2012; Adderley et al., 2015), has the greatest diurnal $T_{\mathrm{s}}$ range (Fig $7 \mathrm{~b}$, median $\Sigma_{\text {roof[dark] }} 290.6 \rightarrow 329.0 \mathrm{~K}$ ). $T_{\mathrm{s}}$ across $\Sigma_{\text {roof[dark] }}$ pixels consistently 
301

302

303

304

305

306

307

308

309

310

311

312

313

314

315

316

317

318

319

320

321

322

323

324

325

326

327

328

329

330

331

332

333

334

335

shows most variation at all times. Driven by insolation, intra-facet $T_{\mathrm{s}}$ variability for $\sum_{\text {rooffdark] }}$ is between 302.1 and $336.3 \mathrm{~K}\left(\mathrm{P}_{5}\right.$ and $\left.\mathrm{P}_{95}\right)$ at 12:00, with $\mathrm{P}_{95}-\mathrm{P}_{5}$ differences consistently over $20 \mathrm{~K}$ between 10:00 and 16:00. The higher albedo of $\Sigma_{\text {roofllight] }}$ surfaces means less shortwave radiation is absorbed which leads to lower $T_{\mathrm{s}}$ with median $\Sigma_{\text {rooflight] }}(313.8 \mathrm{~K})$ at 13:00 being $14.2 \mathrm{~K}$ lower than the coinciding $\Sigma_{\text {roof[dark] }}$ temperature (Fig 7b). Prior to an overcast period in the afternoon (15:30 - 15:55) the two roof types have distinct $T_{\mathrm{s}}$ distributions. The fewer $\Sigma_{\text {rooflight] }}$ pixels are mainly sunlit throughout the day, whereas $\Sigma_{\text {roof[dark] }}$ areas have some within-canopy surfaces affected by prolonged (> $1 \mathrm{~h}$ ) shadowing. Overcast conditions cause the distributions to slightly converge as the contrasting albedos have reduced effect when only diffuse incident solar radiation is incident. The subsequent lower sun angles reduce the overall shortwave radiative forcing.

Grass ( $\left.\sum_{\text {Ground[grass] }}\right) T_{\mathrm{s}}$ has a smaller diurnal range than impervious ground ( $\left.\sum_{\text {Ground[imp.] }}\right)$. Grass temperatures are affected by both evaporative cooling and shadowing from grass blades (i.e. leaf area index is greater than 1) whereas the impervious areas lack moisture (4 days since rainfall). Also, the generally higher heat capacities of $\Sigma_{\text {Ground[imp.] }}$ cause more heat to be stored during the day and released slowly over night. Uncertainty in grass $T_{\mathrm{s}}$ may arise from a potential sample bias as only one camera

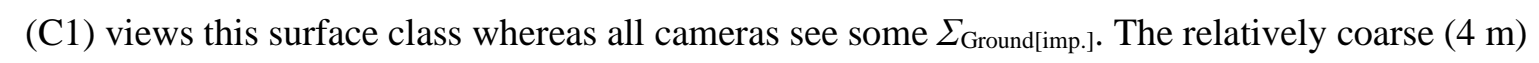
land cover dataset (Lindberg and Grimmond, 2011) may introduce unquantified classification uncertainties.

Considering wall pixels by cardinal orientation, $\Sigma_{\text {East }}\left(\Sigma_{\text {West }}\right)$ pixels are warmest during morning (afternoon), with median $T_{\mathrm{s}}$ reaching 306.1 (310.6) $\mathrm{K}$ at 11:00 (17:00). $\Sigma_{\text {West }}$ surfaces peak at higher temperatures than $\Sigma_{\text {East }}$, as the latter are among the first to be heated in the morning while $\Sigma_{\text {West }}$ surfaces have already been heated throughout the day. $\Sigma_{\text {West }}$ remains warm past sunset (sunset at $\sim$ 18:55 UTC) and is $1.2 \mathrm{~K}$ warmer than $\Sigma_{\text {North }}$ at 23:00 (differences in per-pixel median). This is reasonable given $\Sigma_{\text {North }}$ pixels are mainly shaded throughout the day so that their $T_{\mathrm{s}}$ is consistently low with less variability. Shortly prior to sunset, $\Sigma_{\text {North }}$ surfaces receive a little direct solar irradiation which causes their $T_{\mathrm{s}}$ to be slightly greater than that of $\Sigma_{\text {East }}$ pixels in the evening. The $T_{\mathrm{s}}$ medians across wall orientations consistently differ by over $10 \mathrm{~K}$ between 10:00 and 15:00 (maximum difference is $18.1 \mathrm{~K}$ at $12: 00$ ).

The sampling bias of south-east walls (Section 3) causes the median $T_{\mathrm{s}}$ for $\Sigma_{\text {South }}$ to peak $(315.8 \mathrm{~K})$ at 12:00, i.e. earlier than would be expected for a wall distribution centred around $180^{\circ}$ azimuth. Before sunrise, median $T_{\mathrm{s}}$ differences between wall orientations are less than $0.8 \mathrm{~K}$ but are up to $4.9 \mathrm{~K}$ warmer than $\Sigma_{\text {Roof[dark] }}$ at 01:00 during a clear-sky nocturnal period (consistent with e.g. Lagouarde $e t$ $a l ., 2004)$. During daytime, walls are generally much cooler than roofs. Their complex geometry and material compositions contribute to wall $T_{\mathrm{s}}$ variability. The study area roofs are mostly planar with small features (e.g. chimneys and air conditioning units) whereas walls have many balconies and 
other shade-causing features that reduce their overall temperature. As glass emissivity is unaccounted for, wall $T_{\mathrm{s}}$ may be overestimated (Morrison et al., 2020). Glass and windows (" $\Sigma_{\text {Glass") were not }}$ classified as the resolution of data used to construct the DSM (Google Earth images, Morrison et al., 2020 ) is too coarse. No buildings in the study area have fully glazed walls and glass windows are assumed to be evenly sampled across all cameras.

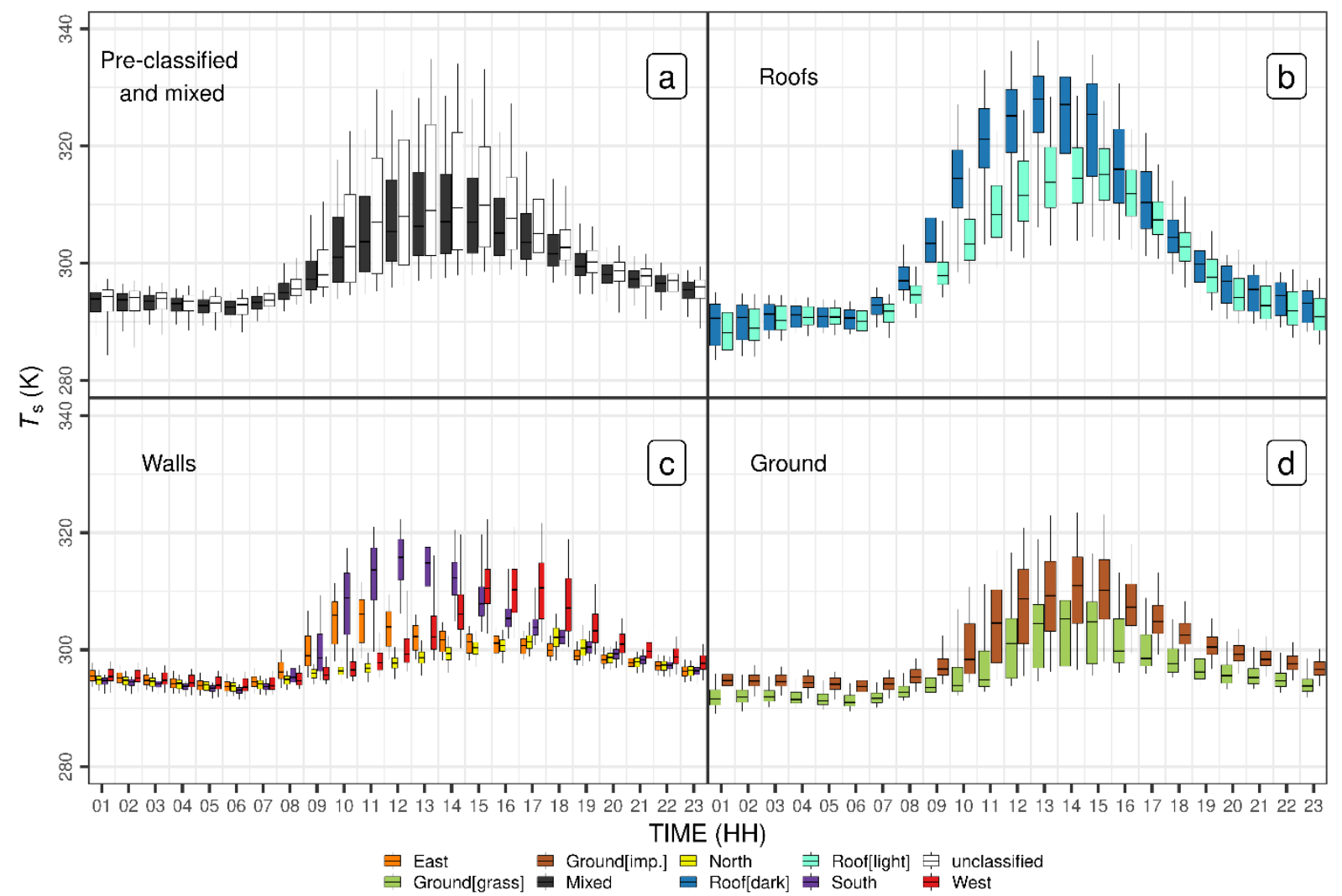

Fig 7. Variability of LWIR camera derived surface temperature $\left(T_{s}\right)$ for $27^{\text {th }}$ August with observations classified as (a) unclassified (white) (except vegetation canopy elements and "masked" and "mixed" (grey) pixels), (b) roofs, (c) walls, and (d) ground. Boxplots use data from all camera images (5 min samples) by group (colour) during $1 \mathrm{~h}$ (e.g. first hour is 00:00 $\rightarrow 00: 55$ for Time (HH) "01" between vertical lines) with interquartile range (box), median (horizontal line) and 5 and 95 percentiles (whiskers) of pixel values.

\subsection{Variability from shortwave irradiance}

$T_{\mathrm{s}}$ by facet (orientation and material) have positive correlation with irradiance using sun-surface geometry (bidirectional reflectance factor, $\overline{\mathrm{BRF}}$ ) (cf. Fig $2 \mathrm{a}, \mathrm{c}$ ). To assess the importance of BRF as a driver for $T_{\mathrm{s}}$ of the low albedo roofs $\left(\sum_{\text {Roof[dark }]}\right)$, the difference between sunlit flat $\left[T_{\mathrm{s}}(\mathrm{BRF} \approx 1)\right]$ and all other binned sun-surface geometry configurations $\left[T_{\mathrm{s}}(\overline{\mathrm{BRF}})\right]$ for roofs (Fig 8$)$ is calculated through a day. Overall, there is clear separation in $T_{\mathrm{s}}$ between $\overline{\mathrm{BRF}}$ bins. At 09:15, median $T_{\mathrm{s}}$ differences between sloped and flat sunlit roofs reach $13.2 \mathrm{~K}\left[T_{\mathrm{s}}(\overline{\mathrm{BRF}}=1.5)-T_{\mathrm{s}}(\mathrm{BRF} \approx 1)\right.$, Fig 8]. Sloped roofs with $\overline{\mathrm{BRF}}<1$ but still sunlit have median $T_{\mathrm{s}}$ up to $23.3 \mathrm{~K}$ cooler than the flat roofs at 11:55. Contributions to the observed $T_{\mathrm{s}}$ variability within each $\overline{\mathrm{BRF}}$ bin at a given timestep are linked to the variable time in sun (Fig 2d), differences in surface albedo and emissivity within the $\Sigma_{\text {Roofdark] }}$ surface property, and uncertainties in atmosphere and emissivity corrections (Morrison et al., 2020). 
During the overcast period $(15: 30-15: 55)$ when $\overline{\mathrm{BRF}}=-1$ for all surfaces, there are smaller differences in $T_{\mathrm{s}}(\overline{\mathrm{BRF}})$ which persists into the evening (Fig 8). A subset of all possible roof slope angles are sampled, meaning some arrangements of sun-surface angles (and therefore $\overline{\mathrm{BRF}}$ ) are not observed for sloped roofs. This results in gaps of $T_{\mathrm{s}}(\overline{\mathrm{BRF}})$ at times (e.g. $T_{\mathrm{s}}(\overline{\mathrm{BRF}}=0.25)$ for around 12:00 $\rightarrow 14: 00)$. Large gaps $(>4 \mathrm{~h})$ for high BRF bins $(\overline{\mathrm{BRF}}>1.25)$ occur with high sun angles (i.e. peaks in $\mathrm{E}_{\lambda}{ }^{\downarrow \text {,dir }}$, Eqn. 1). During these gaps the near-flat roofs are irradiated most and $T_{\mathrm{s}}(\overline{\mathrm{BRF}}=1.25)$ is the highest physically possible bin around midday $( \pm \sim 2.5 \mathrm{~h})$ for the study site latitude and corresponding solar elevation maximum.

Applied to vertical facets (Supplementary material 1), this sun-surface geometry analysis shows most $T_{\mathrm{s}}$ variation is captured by wall orientation (Fig 7c). For ground surfaces, most observations are of flat ground (i.e. $\mathrm{BRF} \approx 1$ ).
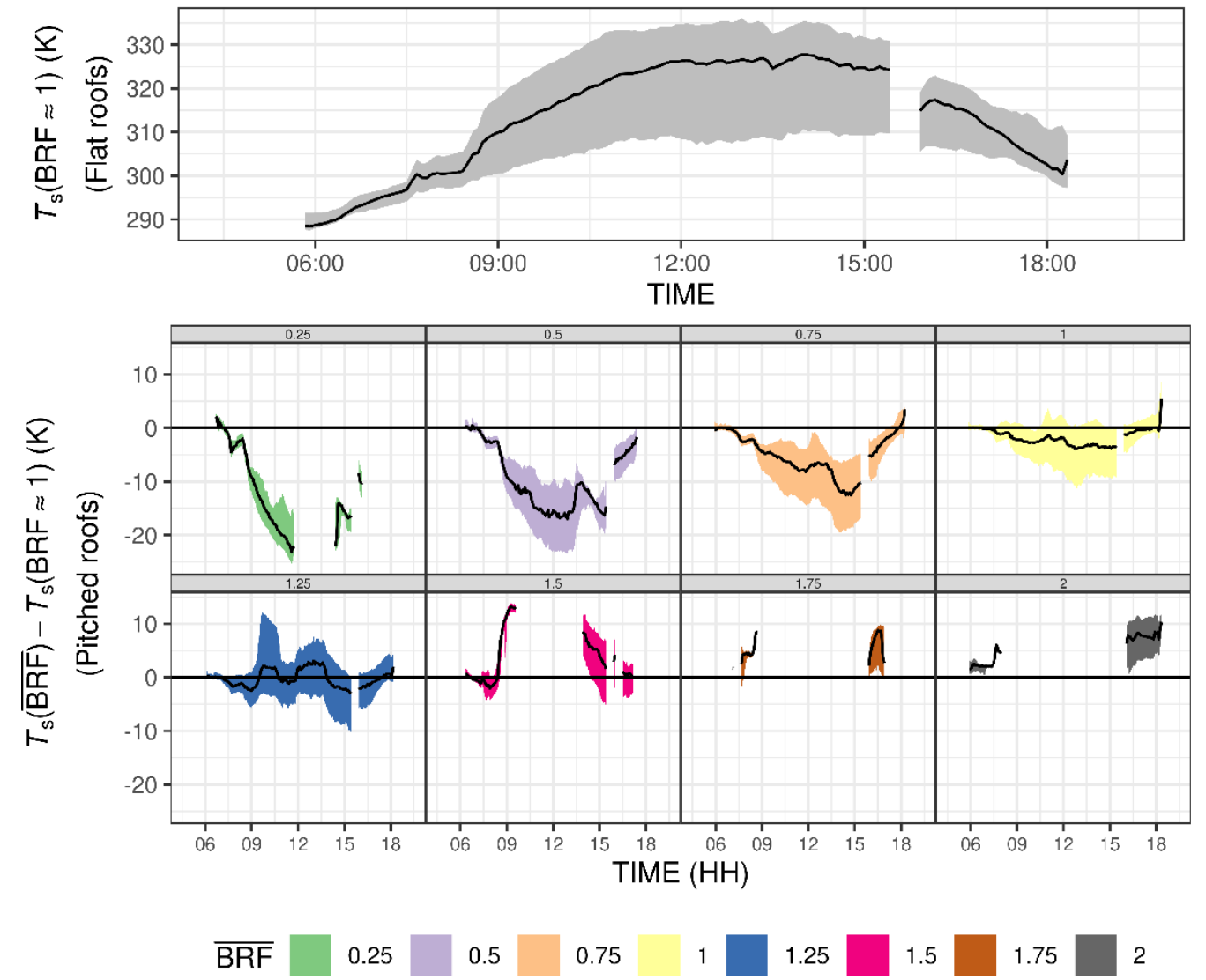

Fig 8. Observed daytime roof surface temperature $\left(T_{s}\right)$ for $27^{\text {th }}$ August for pixels classified with bidirectional reflectance factor (BRF, Schaepman-Strub et al., 2006) (top) equivalent to solar irradiance for a flat surface (BRF $\approx 1$ ) and (bottom) by $\overline{B R F}$ (bin width 0.25 ) as difference from $B R F \approx 1$ (i.e. across all observed sun-surface geometries). DART calculated BRF assuming Lambertian surfaces.

\subsection{Variability from shadow history}

Shadow history has a potentially significant impact on $T_{\mathrm{s}}$ variability given the large and variable thermal inertia of urban materials (e.g. concrete, Arnfield and Grimmond, 1998). We explore the micro-scale persistence effects of shadows on upwelling longwave radiation with thermography 
378 (Meier et al., 2010) with multiple cameras and objectively determined shadow distributions across the 379 images.

380 For the study day, $1.15 \times 10^{6}$ per-pixel cooling events $[\tau(\mathrm{x}, \mathrm{y}, \mathrm{t}, \Sigma)]$ are identified from all cameras

381 (Fig 9). The model fits for each cooling event (Section 2.3) have mean absolute error (MAE) of $0.7 \mathrm{~K}$

382 (ground, roof) or $0.6 \mathrm{~K}$ (walls) and are linear (red dashed line, Fig 9 row 1) across the range of $T_{\mathrm{s}}$

383 differences (approx. $0 \rightarrow 30 \mathrm{~K}$ ). A small number of points have negative differences, indicating the

384 shaded ambient $T_{\mathrm{s}}$ is warmer than the recently shaded $T_{\mathrm{s}}$. Through manual inspection, negative

385 differences for roofs pixels are associated with microscale features in the foreground roof of C6

386 (approx. centre of image, Fig 2a). These roof features may have low emissivity materials or complex

387 geometry unresolved by the DSM. Negative differences for walls are explained by C2's $\Sigma_{\text {West }}(\mathrm{x}, \mathrm{y})$

388 pixels near the building with $\Sigma_{\text {Roofllight] }}$ (Fig 2b). This concrete wall extents above the canyon height so

389 that the relatively high sky view factor and direct solar illumination until sunset are likely causing

390 recently shaded $T_{\mathrm{s}}$ to be lower temperature than the ambient reference. The latter is more

391 representative of warmer inside-canyon walls. Overall, these departures from exponential cooling give

392 the flat "tail" to the scatter (e.g. Fig. 9, wall, row 1), as negative modelled values are not permitted.

393 Negative differences account for $1.3 \%$ of all cooling events (sunlit - shaded difference of $-2.5 \mathrm{~K}$ at

$394 \quad P_{5}$ ). 

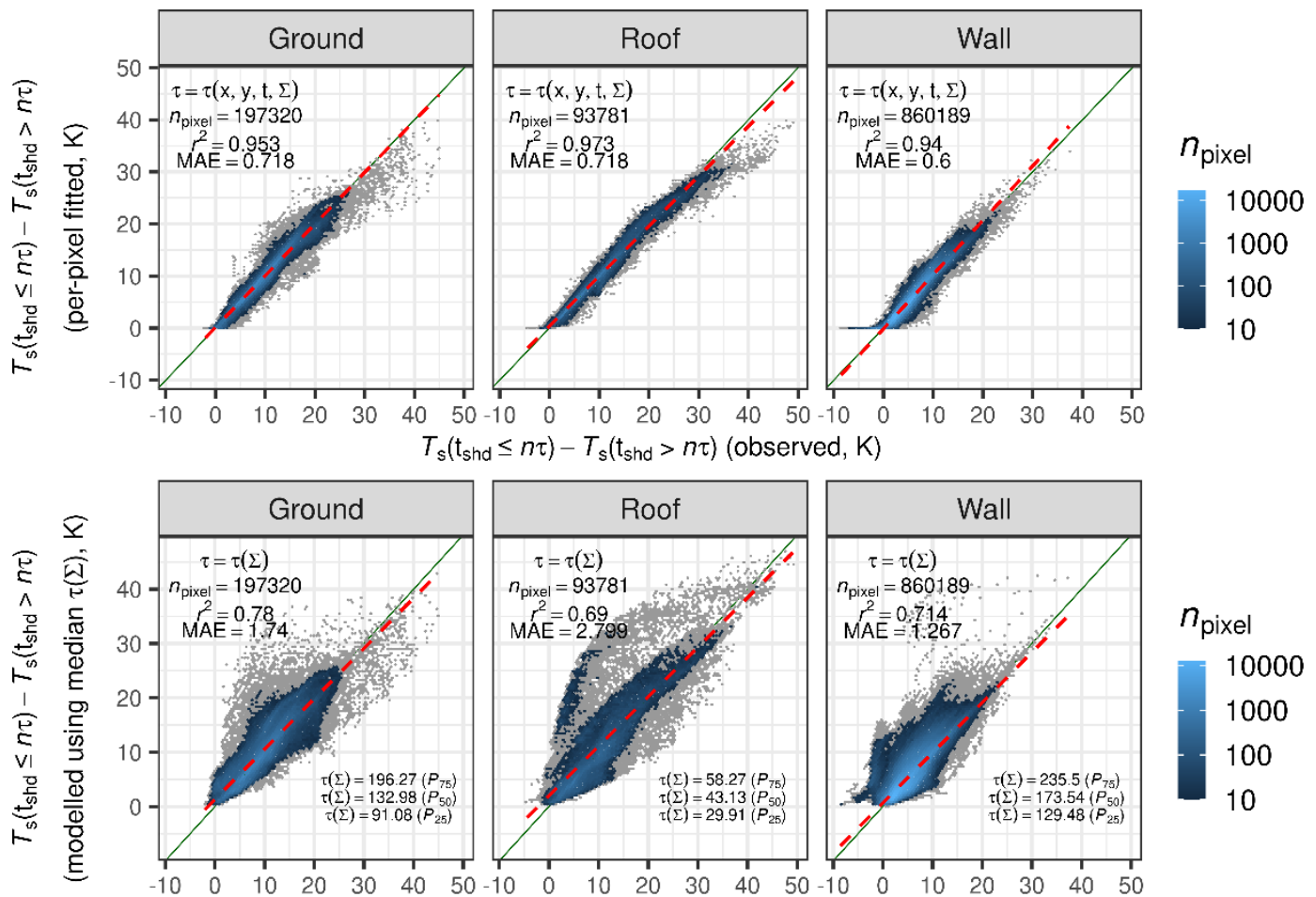

395

397

398

399

400

401

402

403

404

405

406

407

408

409

410

411

412

413

414

415

416

417

418

Fig 9. Surface temperature $\left(T_{s}\right)$ cooling rates observed (x axis) and estimated (using Eqn. 3 ) for each pixel with pixels numbers $\left(\mathrm{n}_{\text {pixel }}\right)$ indicated (colours) with (row 1$)$ fitted time constant $\tau$ per pixel $[\tau(\mathrm{x}, \mathrm{y}, \Sigma)]$ and (row 2 ) modelled time constant as median $\tau(\mathrm{x}, \mathrm{y}, \mathrm{t}, \Sigma)$ per surface type $[\tau(\Sigma)]$ for (column 1) ground (grass and impervious), (column 2) roof (light and dark) and (column 3) walls (N, E, S, W). Statistics: coefficient of determination $\left(\mathrm{r}^{2}\right)$, mean absolute error (MAE, K).

The generalised values of $\tau[\tau(\Sigma)]$ (Fig 9 row 2 labels), determined from the median of $\tau(\mathrm{x}, \mathrm{y}, \mathrm{t}, \Sigma)$ pixels (Section 2.3), allow inter-facet $T_{\mathrm{s}}$ cooling rates to be compared. Roofs generally cool much faster $\left(\tau\left(\Sigma_{\text {Roof }}\right)=43.13 \mathrm{~min}\right)$ than ground $\left(\tau\left(\Sigma_{\text {Ground }}\right)=132.98 \mathrm{~min}\right)$ and walls, which cool around four times slower $\left(\tau\left(\Sigma_{\text {Walls }}\right)=173.54 \mathrm{~min}\right)$. As $\tau(\mathrm{x}, \mathrm{y}, \mathrm{t}, \Sigma)$ is highly variable (e.g. $\tau\left(\Sigma_{\text {Ground }}\right)$ is $91.08 \rightarrow$ 196.27 min for $\left.\mathrm{P}_{25} \rightarrow \mathrm{P}_{75}\right)$, using these generalised median values of $\tau(\mathrm{x}, \mathrm{y}, \mathrm{t}, \Sigma)$ results in a greater spread between observed and modelled results (Fig $9 \mathrm{cf}$. row 1 and 2). There is generally good agreement between observed cooling rates and the generalised modelled results (Fig 9 row 2) but with some large (>10 K) departures when facets have distinctly different thermal properties. Uncertainty is increased for roofs as their shading during daytime can only be from micro-scale roof geometry or from nearby taller buildings (e.g. Fig $2 b$, foreground of $\mathrm{C} 2$ and $\mathrm{C} 3$ ) which is mostly confined to short periods. This reduces the number of pixels available for the ambient $T_{\mathrm{s}}$ estimation (Section 2.3).

Additionally, the emissivity correction uncertainty is greatest for roof surfaces because of the large contrast between LWIR irradiance (from the relatively cool sky) and LWIR exitance (Morrison et al., 2020).

Instances of poor model agreement for ground pixels may arise from the highly contrasting material properties (impervious and grass), whereas for walls the more complex surface geometry may lead to uncertainties in shadow patterns and history. Walls also have a mix of glass and masonry/concrete with their contrasting thermal properties and cooling rates not accounted for. 
The cooling rate model and the spread in Fig 9 (row 2) are summarised (Table 5) using a subset of observations ( $\mathrm{P}_{95}$ differences between recently shaded and ambient after 10 minutes in shade, to represent surfaces that have been heated by the sun throughout the day) modelled at various times in shade using $\tau(\Sigma)$ values. After $10 \mathrm{~min}$, these recently shaded roofs differ most to the ambient temperature ( $27.5 \mathrm{~K}$ warmer than ambient). They exponentially cool the fastest $(2.1 \mathrm{~K}$ warmer than ambient after 90 min using $\tau\left(\Sigma_{\text {Roof }}\right) P_{50}, 0.7 \mathrm{~K} \rightarrow 4.1 \mathrm{~K}$ across interquartile range - IQR) as $\tau\left(\Sigma_{\text {Roof }}\right)$ is lower than $\tau\left(\Sigma_{\text {Wall }}\right)$ and $\tau\left(\Sigma_{\text {Ground }}\right)$. The higher $\tau(\Sigma)$ for walls and ground means there are still significant differences to the ambient temperature after long periods of cooling. After $90 \mathrm{~min}$ the walls are $8.8 \mathrm{~K}$ $(7.1 \mathrm{~K} \rightarrow 10.3 \mathrm{~K} \mathrm{IQR})$ warmer than ambient.

\section{Table 5. Differences in surface temperature $\left(T_{s}\right)$ between recently shaded surfaces (i.e. short tshd - time in shade) and a reference ambient $T_{s}\left(\mathrm{t}_{\mathrm{shd}}>\mathrm{n} \tau\right)$ for $95^{\text {th }}$ percentile $\left(\mathrm{P}_{95}\right)$ of observed thermal camera measurements in central London (27 th August 2017) modelled (Section 2.3) at tshd of 30,60 and 90 min using observationally derived cooling time constants $(\tau)$ for each surface type. E.g. where recently shaded ground is $21.6 \mathrm{~K}$ warmer than ambient after $\mathrm{t}_{\text {shd }}=10$ $\mathrm{min}$, this difference exponentially reduces to $18.6 \mathrm{~K}$ after $30 \mathrm{~min}(17.3 \mathrm{~K} \rightarrow 19.5 \mathrm{~K}$ interquartile range using 196.27 $\min \rightarrow 91.08$ min time constants) using time constant $\tau(\Sigma)=132.98$ (Fig 9 row 2 "Ground" label) and assuming no change in ambient temperature. See Fig 9 for all $\tau(\Sigma)$ percentiles and Eqn. 3 for exponential cooling model.}

\begin{tabular}{|c|c|c|c|c|c|c|c|c|c|c|}
\hline \multirow{3}{*}{$\begin{array}{c}\text { Recently shaded - ambient } \\
T_{\mathrm{s}}\left(\mathrm{t}_{\mathrm{shd}} \leq \mathrm{n} \tau\right)-\boldsymbol{T}_{\mathrm{s}}\left(\mathrm{t}_{\mathrm{shd}}>\mathrm{n} \tau\right)(\mathbf{K})\end{array}$} & \multicolumn{10}{|c|}{ Time in shade $\left(\mathbf{t}_{\text {shd }}\right)$} \\
\hline & \multirow{2}{*}{$\begin{array}{c}10 \text { min } \\
\text { observed }\end{array}$} & \multicolumn{3}{|c|}{$30 \mathrm{~min}$} & \multicolumn{3}{|c|}{$60 \mathrm{~min}$} & \multicolumn{3}{|c|}{$90 \min$} \\
\hline & & $\mathrm{P}_{25}$ & $\mathrm{P}_{50}$ & $\mathrm{P}_{75}$ & $\mathrm{P}_{25}$ & $\mathrm{P}_{50}$ & $\mathrm{P}_{75}$ & $\mathrm{P}_{25}$ & $\mathrm{P}_{50}$ & $\mathrm{P}_{75}$ \\
\hline Ground & 21.6 & 17.3 & 18.6 & 19.5 & 12.5 & 14.8 & 16.7 & 6.5 & 9.4 & 12.3 \\
\hline Roof & 27.5 & 14.1 & 17.3 & 19.5 & 5.2 & 8.6 & 11.7 & 0.7 & 2.1 & 4.1 \\
\hline Walls & 16.5 & 14.1 & 14.7 & 15.2 & 11.2 & 12.4 & 13.3 & 7.1 & 8.8 & 10.3 \\
\hline
\end{tabular}

Previous observations acknowledge that shaded surface temperatures exhibit variation from shadow histories (Voogt, 2008; Morrison et al., 2018), but often aggregate the shaded temperatures to a single value. This work demonstrates the possibility to stratify shaded temperatures instead by shadow history using a simple exponential rate of cooling. Variability in $\tau$ is directly related to variability in heat transfer rate (radiative, convective, and conductive), material heat capacities, density, volume, and overall mass of the observed surface structures. For example, rapid cooling rate of roofs (median cooling time constants $\tau\left(\Sigma_{\text {Roof }}\right)=43.13 \mathrm{~min}$ ) may be explained by a lower mass (cf. walls, Xu and Asawa, 2020) facilitating conductive heat loss, higher sky view factor (facilitating radiative heat transfer), and exposure to higher wind speeds (facilitating convective heat transfer).

\section{Conclusions}

446 Analysis of a fusion of observation (ground-based thermography) and modelling (urban geometry, material properties, sensor views and radiative transfer processes) data on a mainly clear-sky summer day in central London are used to explore various drivers of surface temperature $\left(T_{\mathrm{S}}\right)$ variability. With a very high level of detail surface description and integrated sensor view modelling, the camera source area analysis is unprecedented for such a complex (i.e. realistic) urban setting. General and study specific conclusions about the observation process are:

- Cameras installed on higher buildings have a better vantage and larger source area. 
- In this study, the source area is $15.6 \%$ roofs, $41.6 \%$ walls $(\sim 10 \%$ per cardinal direction) and $22.6 \%$ ground (remainder above ground vegetation).

$\circ$ Even with six cameras the source area is only $9.5 \%$ of the overall area (430 $\mathrm{m} \mathrm{x} 430$ m horizontal extent).

- All pixels are assumed to sample equal portions of the surface yet in reality the surface area covered by a pixel varies across the image due to viewing geometry. Future work should investigate methods to weight aggregated observations by perpixel source area.

Objective image classification separates drivers of $T_{\mathrm{s}}$ variability without requiring manual image classification or statistical inference.

- Observed $T_{\mathrm{s}}$ is highly variable.

$\circ \quad$ In this study the $5^{\text {th }}-95^{\text {th }}$ percentile differences in per-pixel $T_{\mathrm{s}}$ observations reach up to $37.5 \mathrm{~K}$ during daytime.

- Diurnal patterns of $T_{\mathrm{s}}$ for surfaces with different orientation show general agreement with prior studies at similar latitude.

Highly detailed image classification enables $T_{\mathrm{s}}$ variability to be quantified in direct relation to the sun-surface geometry features, including the amount of short- and long-wave radiation incident onto a surface, driving shadow patterns, direct solar irradiance and radiation trapping between buildings.

- Material properties are especially important for roof surfaces with increased access to solar radiation and high exposure to the cold sky. This effect is expected to be particularly important for thermal spaceborne earth observation, where near-nadir remote sensing observations have a view bias of horizontal facets.

- Variability of $T_{\mathrm{s}}$ is driven by surface orientation to the sun of the facet (e.g. walls, roofs, ground) and sub-facet characteristics (e.g. flat or sloped roofs, high or low albedo roofs).

- Variation in surface temperature across a single facet can be of similar magnitude to the variation between the median temperatures of different facet types.

- Across all roof pixels within a given hour (i.e. intra-roof) 5 th -95 th percentile $T_{\mathrm{s}}$ differences are consistently over $20 \mathrm{~K}$ between 10:00 and 16:00 (max $34.2 \mathrm{~K}$ between 11:00 and 11:55)

- Intra-roof variation is driven by sun-surface geometry effects. $T_{\mathrm{s}}$ differences between flat and sloped roofs reach $23.3 \mathrm{~K}$ around midday.

- Pixel-level temperatures of walls stratified by cardinal direction and aggregated to median values (i.e. inter-wall) differ by up to $18.1 \mathrm{~K}$ between north (median $297.7 \mathrm{~K}$ ) and south (median $315.8 \mathrm{~K}$ ) facets around midday. Including roof and ground face $T_{\mathrm{s}}$, 
490 The second important driver of $T_{\mathrm{s}}$ variability are shadows. For the first time, the effect of shadows

491 through time on $T_{\mathrm{s}}$ is quantified across a real convoluted urban surface.

492 - The history of surface shadows greatly affects $T_{\mathrm{s}}$. Recently shaded roof surfaces are up to $27.5 \mathrm{~K}$ warmer than those in shade for long periods.

- Cooling characteristics were modelled from observations using exponential functions with time constants $(\tau)$ estimated relative to long-term shaded surface temperatures. Clear contrasts were found between facet types: roofs on average cool much faster $\tau\left(\Sigma_{\text {Roof }}\right)=43.13 \mathrm{~min}$ than ground $\tau\left(\Sigma_{\text {Ground }}\right)=132.98 \mathrm{~min}$ and walls $\tau\left(\Sigma_{\text {Walls }}\right)=173.54 \mathrm{~min}$.

- Surfaces shaded at sunset will have cooled to within $5 \%$ of the ambient temperature by $\sim 3 \tau$ i.e. over $6 \mathrm{~h}$ and $8.5 \mathrm{~h}$ into the night for ground and walls, respectively.

- This shadow history methodology could be extended to study recently sunlit temperatures.

Material properties determine the amount of incoming energy absorbed.

- Using simple albedo characteristics (i.e. two classes "light" (high albedo) and "dark" (low albedo); excluding any metal or glass) clearly separates observed temperature distributions.

- Dark roofs are up to $14.2 \mathrm{~K}$ warmer during the day as more solar radiation is absorbed.

- Material classification would benefit from more detailed data (e.g. surface optical material properties), particularly for glass and windows which can directionally scatter longwave radiation (e.g. specular reflections) and confound the $T_{\mathrm{s}}$ retrieval (Morrison et al., 2020). Further classification requires more detailed visible imagery from e.g. Google Street view, (Li et al., 2018; Gong et al., 2018), study-specific vehicle traverses (Hilland and Voogt, 2020) or manual inspection (Christen et al., 2012).

Overall, the combination of a relatively large fraction of vegetation, complex geometry and associated $T_{\mathrm{s}}$ distributions give a unique temporally continuous dataset. Observations and the underlying methods for their retrieval and classification could be used as input and to evaluate unstably stratified large eddy simulation modelling (Gronemeier et al., 2017) and building energy balance models (Bueno et al., 2012), or input to radiative transfer models such as DART (Gastellu-Etchegorry et al., 2015) for evaluation of effective thermal anisotropy (Krayenhoff and Voogt, 2016; Morrison et al., 2018; Wang et al., 2018).

518 These data provide useful insights for meso-scale weather and larger scale climate models which simplify the urban surface to facets (Masson, 2000; Harshan et al., 2018) assuming flat roofs with a uniform height (Harman et al., 2004; Krayenhoff and Voogt, 2007). Both the extent of intra-facet surface temperature variability and the net surface cooling rate variability provide some insights into 
the processes that are "averaged" into composite values. Through ensemble modelling, the implications of this variability on averaged flux calculations and therefore weather/climate predictions should be assessed. For many of the larger spatial and temporal extent applications, further observations should assess how representative our study results are with respect to time of year and location (across London, other cities).

\section{Acknowledgements}

This work is funded by Newton Fund/Met Office Climate Science for Service Partnership China (SG), EPSRC DARE (EP/P002331/1), H2020 UrbanFluxes (637519), Met Office Joint Chair and ERC urbisphere 855005. We thank Islington Council (Esther Lamontagne and Paul Stokes) for arranging access to observation sites and Kjell Zum Berge (University of Reading) for assistance with the observations.

\section{References}

Acuña Paz y Miño, J., Lawrence, C. and Beckers, B. (2020) 'Visual metering of the urban radiative environment through $4 \pi$ imagery', Infrared Physics \& Technology, 110, p. 103463. doi: 10.1016/j.infrared.2020.103463.

Adderley, C., Christen, A. and Voogt, J. A. (2015) 'The effect of radiometer placement and view on inferred directional and hemispheric radiometric temperatures of an urban canopy', Atmospheric Measurement Techniques, 8(7), pp. 2699-2714. doi: 10.5194/amt-8-26992015.

Alchapar, N. L., Correa, E. N. and Cantón, M. A. (2014) 'Classification of building materials used in the urban envelopes according to their capacity for mitigation of the urban heat island in semiarid zones', Energy and Buildings, 69, pp. 22-32. doi: 10.1016/j.enbuild.2013.10.012.

Alexander, P. J., Fealy, R. and Mills, G. (2015) 'Spatial validation of an urban energy balance model using multi-temporal remotely sensed surface temperature', in 2015 Joint Urban Remote Sensing Event (JURSE). IEEE, pp. 1-4. doi: 10.1109/JURSE.2015.7120500.

Antoniou, N., Montazeri, H., Neophytou, M. and Blocken, B. (2019) 'CFD simulation of urban microclimate: Validation using high-resolution field measurements', Science of The Total Environment, 695, p. 133743. doi: 10.1016/j.scitotenv.2019.133743.

Arnfield, A. J. and Grimmond, C. S. B. (1998) 'An urban canyon energy budget model and its application to urban storage heat flux modeling', Energy and Buildings, 27(1), pp. 61-68. doi: 10.1016/s0378-7788(97)00026-1.

Asano, K. and Hoyano, A. (1998) 'Application of a new spherical thermography technique to monitoring of outdoor long-wave radiant fields', in Andresen, B. F. and Strojnik, M. (eds), 
p. 317. doi: 10.1117/12.328081.

557

558

559

560

561

562

563

564

565

566

567

568

569

570

571

572

573

574

575

576

577

578

579

580

581

582

583

584

585

586

587

Bird, R. E. and Hulstrom, R. L. (1981) 'Simplified clear sky model for direct and diffuse insolation on horizontal surfaces'. doi: 10.2172/6510849.

Blender (2018) 'Blender 2.79b'. Blender Institute, Amsterdam.

Bueno, B., Pigeon, G., Norford, L. K., Zibouche, K. and Marchadier, C. (2012) 'Development and evaluation of a building energy model integrated in the TEB scheme', Geoscientific Model Development, 5(2), pp. 433-448. doi: 10.5194/gmd-5-433-2012.

Chen, F., Kusaka, H., Bornstein, R., Ching, J., Grimmond, C. S. B., et al. (2011) 'The integrated WRF/urban modelling system: development, evaluation, and applications to urban environmental problems', International Journal of Climatology, 31(2), pp. 273-288. doi: 10.1002/joc. 2158 .

Christen, A., Meier, F. and Scherer, D. (2012) 'High-frequency fluctuations of surface temperatures in an urban environment', Theoretical and Applied Climatology, 108(1-2), pp. 301-324. doi: 10.1007/s00704-011-0521-x.

Crawley, D. B., Lawrie, L. K., Winkelmann, F. C., Buhl, W. F., Huang, Y. J., et al. (2001) 'EnergyPlus: creating a new-generation building energy simulation program', Energy and Buildings, 33(4), pp. 319-331. doi: 10.1016/S0378-7788(00)00114-6.

Evans, S., Hudson-Smith, A. and Batty, M. (2011) '3-D GIS: Virtual London and beyond', Cybergeo. doi: 10.4000/cybergeo.2871.

Fröhlich, D., Gangwisch, M. and Matzarakis, A. (2019) 'Effect of radiation and wind on thermal comfort in urban environments - Application of the RayMan and SkyHelios model', Urban Climate, 27, pp. 1-7. doi: 10.1016/j.uclim.2018.10.006.

Gaitani, N., Burud, I., Thiis, T. and Santamouris, M. (2017) 'High-resolution spectral mapping of urban thermal properties with Unmanned Aerial Vehicles', Building and Environment, 121, pp. 215-224. doi: 10.1016/j.buildenv.2017.05.027.

Gastellu-Etchegorry, J. P., Yin, T., Lauret, N., Cajgfinger, T., Gregoire, T., et al. (2015) 'Discrete anisotropic radiative transfer (DART 5) for modeling airborne and satellite spectroradiometer and LIDAR acquisitions of natural and urban landscapes', Remote Sensing, 7(2), pp. 1667-1701. doi: 10.3390/rs70201667.

Gastellu-Etchegorry, J. P., Grau, E. and Lauret, N. (2012) 'DART: A 3D Model for Remote Sensing Images and Radiative Budget of Earth Surfaces', in Modeling and Simulation in Engineering. InTech. doi: 10.5772/31315. 
Gong, F. Y., Zeng, Z. C., Zhang, F., Li, X., Ng, E., et al. (2018) 'Mapping sky, tree, and building view factors of street canyons in a high-density urban environment', Building and Environment, 134(February), pp. 155-167. doi: 10.1016/j.buildenv.2018.02.042.

Google (2019) ‘Google Earth Pro’, Google. Google.

Gronemeier, T., Raasch, S. and Ng, E. (2017) 'Effects of unstable stratification on ventilation in Hong Kong', Atmosphere, 8(9), pp. 1-15. doi: 10.3390/atmos8090168.

Harman, I. N., Best, M. J. and Belcher, S. E. (2004) 'Radiative exchange in an urban street canyon', Boundary-Layer Meteorology, 110(2), pp. 301-316. doi: 10.1023/A:1026029822517.

Harshan, S., Roth, M., Velasco, E. and Demuzere, M. (2018) 'Evaluation of an urban land surface scheme over a tropical suburban neighborhood', Theoretical and Applied Climatology, 133(3-4), pp. 867-886. doi: 10.1007/s00704-017-2221-7.

Hartley, R. I. and Zisserman, A. (2004) Multiple View Geometry in Computer Vision. Second. Cambridge University Press, ISBN: 0521540518.

Hartz, D. A., Prashad, L., Hedquist, B. C., Golden, J. and Brazel, A. J. (2006) 'Linking satellite images and hand-held infrared thermography to observed neighborhood climate conditions', Remote Sensing of Environment, 104(2), pp. 190-200. doi: 10.1016/j.rse.2005.12.019.

Hénon, A., Mestayer, P. G., Lagouarde, J. P. and Voogt, J. A. (2012) 'An urban neighborhood temperature and energy study from the CAPITOUL experiment with the Solene model: Part 2: Influence of building surface heterogeneities', Theoretical and Applied Climatology, 110(1-2), pp. 197-208. doi: 10.1007/s00704-012-0616-z.

Hilland, R. V. J. and Voogt, J. A. (2020) 'The effect of sub-facet scale surface structure on wall brightness temperatures at multiple scales', Theoretical and Applied Climatology, 140(1-2), pp. 767-785. doi: 10.1007/s00704-020-03094-7.

Hu, L. and Wendel, J. (2019) 'Analysis of urban surface morphologic effects on diurnal thermal directional anisotropy', ISPRS Journal of Photogrammetry and Remote Sensing, 148(December 2018), pp. 1-12. doi: 10.1016/j.isprsjprs.2018.12.004.

Kanda, M., Kawai, T., Kanega, M., Moriwaki, R., Narita, K., et al. (2005) 'A simple energy balance model for regular building arrays', Boundary-Layer Meteorology, 116(3), pp. 423-443. doi: 10.1007/s10546-004-7956-x.

Krayenhoff, E. S., Jiang, T., Christen, A., Martilli, A., Oke, T. R., et al. (2020) 'A multi-layer urban canopy meteorological model with trees (BEP-Tree): Street tree impacts on pedestrian-level climate', Urban Climate, 32(July 2019), p. 100590. doi: 10.1016/j.uclim.2020.100590. 
Krayenhoff, E. and Voogt, J. (2016) 'Daytime Thermal Anisotropy of Urban Neighbourhoods: Morphological Causation', Remote Sensing, 8(2), p. 108. doi: 10.3390/rs8020108.

Krayenhoff, S. E. and Voogt, J. A. (2007) 'A microscale three-dimensional urban energy balance model for studying surface temperatures', Boundary-Layer Meteorology, 123(3), pp. 433461. doi: 10.1007/s10546-006-9153-6.

Kusaka, H. and Kimura, F. (2004) 'Coupling a single-layer urban canopy model with a simple atmospheric model: Impact on urban heat island simulation for an idealized case', Journal of the Meteorological Society of Japan, 82(1), pp. 67-80. doi: 10.2151/jmsj.82.67.

Lagouarde, J. P., Moreau, P., Irvine, M., Bonnefond, J. M., Voogt, J. A., et al. (2004) ‘Airborne experimental measurements of the angular variations in surface temperature over urban areas: Case study of Marseille (France)', Remote Sensing of Environment, 93(4), pp. 443462. doi: 10.1016/j.rse.2003.12.011.

Lee, S., Moon, H., Choi, Y. and Yoon, D. K. (2018) 'Analyzing thermal characteristics of urban streets using a thermal imaging camera: A case study on commercial streets in Seoul, Korea', Sustainability (Switzerland), 10(2), pp. 1-21. doi: 10.3390/su10020519.

Li, X., Ratti, C. and Seiferling, I. (2018) 'Quantifying the shade provision of street trees in urban landscape: A case study in Boston, USA, using Google Street View', Landscape and Urban Planning, 169(August 2017), pp. 81-91. doi: 10.1016/j.landurbplan.2017.08.011.

Lindberg, F. and Grimmond, C. S. B. (2011) 'The influence of vegetation and building morphology on shadow patterns and mean radiant temperatures in urban areas: model development and evaluation', Theoretical and Applied Climatology, 105(3-4), pp. 311-323. doi: 10.1007/s00704-010-0382-8.

Masson, V. (2000) 'A physically-based scheme for the urban energy budget in atmospheric models', Boundary-Layer Meteorology, 94(3), pp. 357-397. doi: 10.1023/A:1002463829265.

Meier, F., Scherer, D., Richters, J. and Christen, A. (2011) 'Atmospheric correction of thermalinfrared imagery of the 3-D urban environment acquired in oblique viewing geometry', Atmospheric Measurement Techniques, 4(5), pp. 909-922. doi: 10.5194/amt-4-909-2011.

Meier, F., Scherer, D. and Richters, J. (2010) 'Determination of persistence effects in spatiotemporal patterns of upward long-wave radiation flux density from an urban courtyard by means of Time-Sequential Thermography', Remote Sensing of Environment, 114(1), pp. 2134. doi: 10.1016/j.rse.2009.08.002.

Morrison, W., Kotthaus, S., Grimmond, C. S. B., Inagaki, A., Yin, T., et al. (2018) 'A novel method 
to obtain three-dimensional urban surface temperature from ground-based thermography', Remote Sensing of Environment, 215(December 2017), pp. 268-283. doi: 10.1016/j.rse.2018.05.004.

Morrison, W., Yin, T., Lauret, N., Guilleux, J., Kotthaus, S., et al. (2020) 'Atmospheric and emissivity corrections for ground-based thermography using 3D radiative transfer modelling', Remote Sensing of Environment, 237(December 2019), p. 111524. doi: 10.1016/j.rse.2019.111524.

Naughton, J. and McDonald, W. (2019) 'Evaluating the Variability of Urban Land Surface Temperatures Using Drone Observations', Remote Sensing, 11(14), p. 1722. doi: $10.3390 /$ rs 11141722 .

Offerle, B., Grimmond, C. S. B., Fortuniak, K. and Pawlak, W. (2006) 'Intraurban differences of surface energy fluxes in a central European City', Journal of Applied Meteorology and Climatology, 45(1), pp. 125-136. doi: 10.1175/JAM2319.1.

Optris GmbH (2018) ‘Optris PI Operator’s Manual'. Germany.

Pearlmutter, D., Berliner, P. and Shaviv, E. (2006) 'u', Building and Environment, 41(6), pp. 783795. doi: 10.1016/j.buildenv.2005.03.017.

Perpinán, O. (2012) ' $\{$ solaR $\}$ : Solar Radiation and Photovoltaic Systems with $\{\mathrm{R}\}$ ', Journal of Statistical Software, 50(9), pp. 1-32. Available at: http://www.jstatsoft.org/v50/i09/.

Porson, A., Clark, P. A., Harman, I. N., Best, M. J. and Belcher, S. E. (2010) 'Implementation of a new urban energy budget scheme in the MetUM. Part I: Description and idealized simulations', Quarterly Journal of the Royal Meteorological Society, 136(651), pp. 15141529. doi: 10.1002/qj.668.

Rotach, M. W., Vogt, R., Bernhofer, C., Batchvarova, E., Christen, A., et al. (2005) 'BUBBLE - An urban boundary layer meteorology project', Theoretical and Applied Climatology, 81(3-4), pp. 231-261. doi: 10.1007/s00704-004-0117-9.

Schaepman-Strub, G., Schaepman, M. E., Painter, T. H., Dangel, S. and Martonchik, J. V. (2006) 'Reflectance quantities in optical remote sensing-definitions and case studies', Remote Sensing of Environment, 103(1), pp. 27-42. doi: 10.1016/j.rse.2006.03.002.

Toparlar, Y., Blocken, B., Vos, P., van Heijst, G. J. F., Janssen, W. D., et al. (2015) 'CFD simulation and validation of urban microclimate: A case study for Bergpolder Zuid, Rotterdam', Building and Environment, 83, pp. 79-90. doi: 10.1016/j.buildenv.2014.08.004.

Toparlar, Y., Blocken, B., Maiheu, B. and van Heijst, G. J. F. (2017) 'A review on the CFD analysis 

doi: 10.1016/j.rser.2017.05.248

Vollmer, M. (2009) 'Newton's law of cooling revisited', European Journal of Physics, 30(5), pp. 1063-1084. doi: 10.1088/0143-0807/30/5/014.

Vollmer, M. and Möllmann, K.-P. (2017) Infrared Thermal Imaging. Weinheim, Germany: WileyVCH Verlag GmbH \& Co. KGaA. doi: 10.1002/9783527693306.

Voogt, J. A. (2008) 'Assessment of an Urban Sensor View Model for thermal anisotropy', Remote Sensing of Environment, 112(2), pp. 482-495. doi: 10.1016/j.rse.2007.05.013.

Voogt, J. A. and Grimmond, C. S. B. (2000) 'Modeling surface sensible heat flux using surface radiative temperatures in a simple urban area', Journal of Applied Meteorology, 39(10), pp. 1679-1699. doi: 10.1175/1520-0450-39.10.1679.

Voogt, J. a. and Oke, T. R. (1997) 'Complete Urban Surface Temperatures', Journal of Applied Meteorology, 36(9), pp. 1117-1132. doi: 10.1175/15200450(1997)036<1117:CUST>2.0.CO;2.

Wang, D., Chen, Y. and Zhan, W. (2018) 'A geometric model to simulate thermal anisotropy over a sparse urban surface (GUTA-sparse)', Remote Sensing of Environment, 209(19), pp. 263274. doi: 10.1016/j.rse.2018.02.051.

$\mathrm{Xu}, \mathrm{X}$. and Asawa, T. (2020) 'Systematic numerical study on the effect of thermal properties of building surface on its temperature and sensible heat flux', Building and Environment, 168(October 2019). doi: 10.1016/j.buildenv.2019.106485. 